\title{
Year-round retrievals of trace gases in the Arctic using the Extended-range Atmospheric Emitted Radiance Interferometer
}

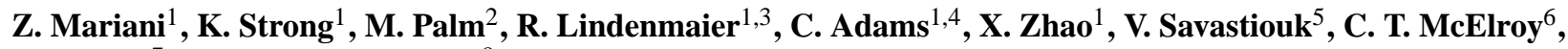 \\ F. Goutail ${ }^{7}$, and J. R. Drummond ${ }^{8}$ \\ ${ }^{1}$ Department of Physics, University of Toronto, Toronto, Canada \\ ${ }^{2}$ Department of Physics, University of Bremen, Bremen, Germany \\ ${ }^{3}$ Physics Division, Los Alamos National Laboratory, Los Alamos, USA \\ ${ }^{4}$ Department of Physics \& Engineering, University of Saskatoon, Saskatoon, Canada \\ ${ }^{5}$ Full Spectrum Science Inc., Toronto, Ontario, Canada \\ ${ }^{6}$ Department of Earth \& Space Science and Engineering, York University, Toronto, Ontario, Canada \\ ${ }^{7}$ LATMOS, CNRS-Université Versailles St. Quentin, Guyancourt, France \\ ${ }^{8}$ Department of Physics \& Atmospheric Science, Dalhousie University, Halifax, NS, Canada
}

Correspondence to: Z. Mariani (zmariani@atmosp.physics.utoronto.ca), K. Strong (strong@ atmosp.physics.utoronto.ca), M. Palm (mathias@iup.physik.uni-bremen.de), R. Lindenmaier (rodica@atmosp.physics.utoronto.ca),

C. Adams (cadams@ physics.utoronto.ca),X.Zhao (xizhao@atmosp.physics.utoronto.ca), V. Savastiouk (volodya@io3.ca),

C. T. McElroy (c.t.mcelroy@gmail.com), F. Goutail (florence.goutail@aerov.jussieu.fr),

and J. R. Drummond (james.drummond@dal.ca)

Received: 4 December 2012 - Published in Atmos. Meas. Tech. Discuss.: 16 January 2013

Revised: 9 May 2013 - Accepted: 13 May 2013 - Published: 14 June 2013

\begin{abstract}
The Extended-range Atmospheric Emitted Radiance Interferometer (E-AERI) was installed at the Polar Environment Atmospheric Research Laboratory (PEARL) at Eureka, Nunavut, Canada in October 2008. Spectra from the E-AERI provide information about the radiative balance and budgets of trace gases in the Canadian high Arctic. Measurements are taken every 7 min year-round, including polar night when the solar-viewing spectrometers at PEARL are not operated. This allows E-AERI measurements to fill the gap in the PEARL dataset during the four months of polar night. Measurements were taken year-round in 2008-2009 at the PEARL Ridge Lab, which is $610 \mathrm{~m}$ a.s.l. (above sealevel), and from 2011 onwards at the Zero-Altitude PEARL Auxiliary Lab (OPAL), which is at sea level $15 \mathrm{~km}$ from the Ridge Lab. Total columns of $\mathrm{O}_{3}, \mathrm{CO}, \mathrm{CH}_{4}$, and $\mathrm{N}_{2} \mathrm{O}$ have been retrieved using a modified version of the SFIT2 retrieval algorithm adapted for emission spectra. This provides the first ground-based nighttime measurements of these species at Eureka. Changes in the total columns driven by photochemistry and dynamics are observed. Analyses of E-AERI retrievals indicate accurate spectral fits (root-mean-square
\end{abstract}

residuals consistent with noise) and a 10-15\% uncertainty in the total column, depending on the trace gas. $\mathrm{O}_{3}$ comparisons between the E-AERI and a Bruker IFS 125HR Fourier transform infrared (FTIR) spectrometer, three Brewer spectrophotometers, two UV-visible ground-based spectrometers, and a System D'Analyse par Observations Zenithales (SAOZ) at PEARL are made from 2008-2009 and for 2011. 125HR $\mathrm{CO}, \mathrm{CH}_{4}$, and $\mathrm{N}_{2} \mathrm{O}$ columns are also compared with the E-AERI measurements. Mean relative differences between the E-AERI and the other spectrometers are 1-10\% (14\% is for the un-smoothed profiles), which are less than the EAERI's total column uncertainties. The E-AERI $\mathrm{O}_{3}$ and $\mathrm{CO}$ measurements are well correlated with the other spectrometers $(r>0.92$ with the 125HR). The $24 \mathrm{~h}$ diurnal cycle and 365-day seasonal cycle of $\mathrm{CO}$ are observed and their amplitudes are quantified by the E-AERI (6-12 and 46\%, respectively). The seasonal variability of $\mathrm{H}_{2} \mathrm{O}$ has an impact on the retrievals, leading to larger uncertainties in the summer months. Despite increased water vapour at the lower-altitude site OPAL, measurements at OPAL are consistent with measurements at PEARL. 


\section{Introduction}

Ground-based Fourier transform infrared (FTIR) spectrometers are deployed across the globe to make measurements of atmospheric composition by absorption and emission spectroscopy. The Extended-range Atmospheric Emitted Radiance Interferometer (E-AERI) is a moderate resolution $\left(1 \mathrm{~cm}^{-1}\right)$ FTIR spectrometer for measuring the absolute downwelling infrared emission from the atmosphere between 400 and $3000 \mathrm{~cm}^{-1}$. The large number of trace gases that have emission features in the infrared enable simultaneous measurements of different trace gases from the ground. For instance, the ability to use Atmospheric Emitted Radiance Interferometer (AERI) measurements to retrieve $\mathrm{CO}$ total column concentrations with high sensitivity to the lower troposphere has recently been demonstrated (Yurganov et al., 2010).

The Canadian Network for the Detection of Atmospheric Change (CANDAC) has equipped the Polar Environment Atmospheric Research Laboratory (PEARL), which is located at Eureka, Nunavut $\left(80^{\circ} \mathrm{N}, 86^{\circ} \mathrm{W}\right)$, with several spectrometers that measure atmospheric composition. One of these instruments is the E-AERI, which is used for studies of the Arctic radiation budget and atmospheric trace gases. Details of the instrument's design, calibration, installation and performance are provided in Mariani et al. (2012). The E-AERI was installed at the PEARL Ridge Lab (610 m a.s.l.) in October 2008 and acquired one year of measurements before being moved $15 \mathrm{~km}$ to the Zero-altitude PEARL Auxiliary Lab (OPAL), which is at an altitude of $10 \mathrm{~m}$. The geography surrounding the two measurement sites is seen in Fig. 1. EAERI total column retrievals of $\mathrm{O}_{3}, \mathrm{CO}, \mathrm{CH}_{4}$, and $\mathrm{N}_{2} \mathrm{O}$ from these two measurement sites are discussed in this paper.

The E-AERI started taking measurements of downwelling radiance at OPAL in February 2011 (where it has since remained operational) to determine concentrations of tropospheric trace gases from sea level and to investigate cooling in the 20-micron region. From a climatology of radiosonde water vapour data, 10-20\% (winter-summer) of the water vapour at Eureka resides in the first $610 \mathrm{~m}$, making OPAL's location essential for future radiative budget and water vapour studies. The difficulty in fitting $\mathrm{H}_{2} \mathrm{O}$ emission, however, is a source of error in the E-AERI trace gas retrievals, as will be discussed. The impact of the increased water vapour on trace gas retrievals at OPAL will be evaluated by comparing them to the retrievals performed at the PEARL Ridge Lab.

There are several other spectrometers installed at PEARL, all of which are solar-absorption instruments. The Bruker IFS 125HR FTIR spectrometer, two UV-visible GroundBased Spectrometers (GBSs), three Brewer spectrophotometers, and a System D'Analyse par Observations Zenithales (SAOZ) spectrometer were used to compare total column measurements with the E-AERI and are described in more detail in Sect. 2.4. These provide an extensive dataset that

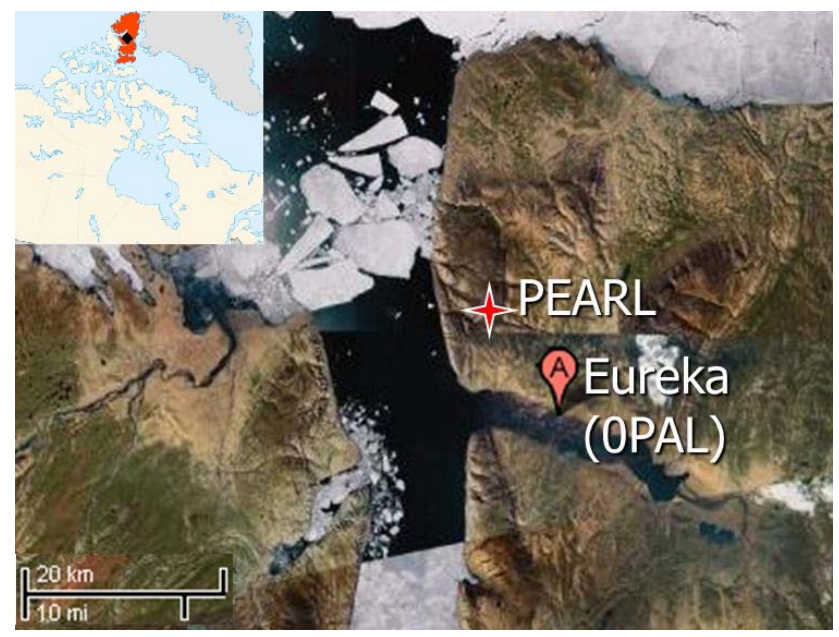

Fig. 1. Satellite composite image of Eureka on Ellesmere Island (insert: highlighted in red, black diamond is Eureka), Nunavut, Canada in the early summer. The PEARL Ridge Lab and OPAL are separated by $15 \mathrm{~km}$ and their locations are indicated on the image. Image: ${ }^{\complement} 2013$ Google, ${ }^{\complement} 2013$ TerraMetrics, ${ }^{\circledR} 2013$ Wikipedia.

will continue to be used to evaluate E-AERI trace gas retrievals during sun-lit months. During nighttime conditions (such as the four months of polar night), the E-AERI is the only spectrometer operating at Eureka that can obtain total column measurements of trace gases; hence it will be used to fill a significant gap in the PEARL dataset.

The SFIT2 retrieval code (Pougatchev et al., 1995; Rinsland et al., 1998), which is widely used in the Network for the Detection of Atmospheric Composition Change (NDACC) Infrared Working Group (IRWG) (e.g. the PEARL 125HR retrievals use SFIT2), has recently been modified so that it can be applied to infrared emission spectra, such as those recorded by the E-AERI. This new emission version of SFIT2 will be implemented in the next version of the code, SFIT4. E-AERI total column retrievals of $\mathrm{O}_{3}, \mathrm{CO}, \mathrm{CH}_{4}$ and $\mathrm{N}_{2} \mathrm{O}$ have been performed year-round using this new version of SFIT2.

Eureka is an excellent location for various scientific studies, ranging from polar ozone depletion, to satellite validation, to characterizing long-range transport. The conditions in the Arctic atmosphere can be favourable for the heterogeneous reactions that deplete stratospheric $\mathrm{O}_{3}$ in the cold Arctic polar vortex. $\mathrm{N}_{2} \mathrm{O}$ is an important greenhouse gas and has been shown to be the most important ozone-depleting substance emitted today (Ravishankara et al., 2009). Measurements of $\mathrm{O}_{3}$ and $\mathrm{N}_{2} \mathrm{O}$, particularly during the wintertime formation of the polar vortex, can provide insight into chemical and dynamical processes occurring in this rapidly changing region. Such monitoring at Eureka started in 1993 with the installation of a Bomem DA8 FTIR by Environment Canada (Fast et al., 2011) with regular intensive monitoring using the 125HR (and other) spectrometers beginning in 
2006 after the establishment of PEARL (Fraser et al., 2009; Batchelor et al., 2009). PEARL is uniquely situated in close proximity to frequent overpasses by satellites, such as the Atmospheric Chemistry Experiment (ACE), making groundbased measurements at this site particularly useful for satellite validation purposes (Batchelor et al., 2010; Adams et al., 2012a). The products of biomass burning over northern Eurasia, which has increased significantly over the past $100 \mathrm{yr}$ due to human activities, can also be transported to the Arctic and result in CO total column enhancements (Stohl, 2006; Warneke et al., 2010). This provides a growing source of chemically and radiatively active gases such as $\mathrm{CO}_{2}, \mathrm{CH}_{4}$ and other hydrocarbons that can be measured by groundbased spectrometers such as the E-AERI. Photochemistry has a noticeable effect on the budget of trace gases above Eureka: $24 \mathrm{~h}$ darkness (polar night) occurs from mid-October to mid-February and rapidly transitions to $24 \mathrm{~h}$ sunlight (polar day) from late-April to late-August. The seasonal variability of these trace gases can be measured by the E-AERI at PEARL; for instance, the polar vortex is frequently above Eureka in the spring, with vortex dynamics playing a key role in the ozone budget, whereas in the summer the variability in trace gases is largely dependent on transport from lower latitudes.

This paper describes the new emission version of SFIT2 and its application, outlines AERI trace gas retrievals using SFIT2 (which is applicable to all other AERIs deployed across the globe), and provides the first continuous polar night trace gas measurements at Eureka. E-AERI measurements and modifications to the SFIT2 retrieval algorithm are discussed in Sect. 2. Section 3 outlines the retrieval methodology, including the spectral regions of interest ("miniwindows") and error analysis. Results from E-AERI trace gas measurements made at the PEARL Ridge Lab from October 2008 to September 2009 are shown in Sect. 4; results from measurements at OPAL from February to December 2011 are shown in Sect. 5. Comparisons with the other spectrometers at PEARL, as well as an investigation of the diurnal and interannual variability of these trace gases above Eureka are provided in these two sections. A summary and conclusions are given in Sect. 6.

\section{Measurements}

\subsection{E-AERI radiances}

The E-AERI measures zenith-sky thermal emission from the atmosphere using ABB's MR-300 series Fourier transform spectrometer with a maximum optical path difference (OPD) of $1 \mathrm{~cm}$, providing an unapodized resolution (defined here as $1 /$ maximum OPD) of $1 \mathrm{~cm}^{-1}$. Its measured radiances have undergone several performance evaluations, including comparisons with other AERI systems at the University of Wisconsin and PEARL, as well as model simulations to ensure measurement reliability (Mariani et al., 2012). The E-AERI operated continuously at the PEARL Ridge Lab from 22 October 2008 to 20 September 2009, except when precipitation occurred, during instrument maintenance, and when a software error caused the hatch to close erroneously (which has since been fixed).

No measurements were made in 2010; during this time the E-AERI was removed from the PEARL Ridge Lab and installed in the same thru-wall configuration at OPAL, while the Stirling-cycle cooler used on the detector was upgraded to a new THALES Stirling-cycle cryogenic cooler, the sensorcontroller digital multimeter was re-calibrated by its manufacturer (Agilent), and the entire instrument underwent calibration and re-certification testing according to the University of Wisconsin Space Science and Engineering Centre's (UW-SSEC) standards and procedures. This ensured the instrument's specifications and performance at OPAL matched those at PEARL. Measurements at OPAL started on 16 February 2011 and continue to this day. In 2011, there were three periods with no measurements due to instrument issues and maintenance. The instrument was re-certified according to UW-SSEC standards during a service visit in November 2011 to once again ensure instrument performance stability and measurement reliability.

The E-AERI is fully automated and produces 248 coadded spectra every $7 \mathrm{~min}$ except during precipitation events, when the scene-view hatch is automatically closed. The instrument's field of view is carefully mapped to correct for the small effects of instrument self-apodization on the Instrument Line Shape (ILS). The result is an "ideal" sinc function ILS, which is described in more detail in Knuteson et al. (2004) along with the correction methodology used on the spectra. For this work, spectra collected in a $1 \mathrm{~h}$ window are averaged to produce a dataset of hourly averaged radiances to improve the signal-to-noise ratio; typically eight spectra are averaged in a $1 \mathrm{~h}$ window. Retrievals of trace gases when clouds are present are difficult due to the increased emission from cloud particles, causing a large increase in baseline radiance (Mariani et al., 2012). This increased emission dwarfs the spectral signature from the trace gases of interest. Thus cloudy measurement periods are filtered using a maximum radiance tolerance criterion, which is season dependent, in the cloud-sensitive region $\left(750-1200 \mathrm{~cm}^{-1}\right)$. The accuracy of the cloud-filtering process has been confirmed by cross checking with the millimeter cloud radar and meteorological observations at Eureka. Thus all measurements of trace gases presented here were recorded during clear-sky conditions.

\subsection{Comparisons to other ground-based emission spectrometers}

The E-AERI has been designed to take emission measurements over a broad region of the infrared spectrum that includes atmospheric trace gas emission lines and the socalled "dirty window" around $400 \mathrm{~cm}^{-1}$ where much of the 
near-surface infrared cooling to space occurs in the Arctic (this spectral region becomes more transparent due to the extremely cold and dry Arctic atmosphere) (Clough et al., 1992; Tobin et al., 1999). Other ground-based emission spectrometers are used to study the emission spectroscopy of distant stars using near-infrared emission spectrometers (e.g. Waldmann et al., 2012) or are designed to measure different atmospheric trace gases (for instance, millimeterwave radiometers (MWRs) such as the Kiruna millimeterwave radiometer (KIMRA); Raffalski et al., 2005). MWRs differ from the E-AERI in that they require their detectors to be cooled to significantly lower temperatures $(<35 \mathrm{~K})$ than the E-AERI $(<70 \mathrm{~K})$ in order to detect the faint millimeterwave emission lines. MWRs typically measure weaker emission signals but have higher spectral resolution than the EAERI. The E-AERI is also zenith viewing, permitting measurements directly above the site's location, whereas many emission spectrometers (including some MWRs and older variants of the E-AERI) use a slant path to increase the emission signal. The E-AERI software system performs all necessary data calibration and quality control in real time and, like most MWRs, is fully automated and can be controlled remotely.

Emission spectrometers can be deployed off the ground and utilize different viewing geometries. For instance, the Michelson Interferometer for Passive Atmospheric Sounding (MIPAS) instrument on Envisat and its balloon-borne version (MIPAS-B) measure vertical profiles of trace gases using infrared limb-emission sounding (Fischer and Oelhaf, 1996). The Spectroscopy of the Atmosphere using Far InfraRed Emission-Airborne (SAFIRE-A) operates in the far-infrared spectral region, making limb sounding observations of atmospheric emission from high altitude aircraft (Bianchini et al., 2003). The Scanning Infrared Gas Imaging System (SIGIS) is a ground-based thermal emission infrared spectrometer that measures volcanic $\mathrm{SO}_{2}$ and $\mathrm{SiF}_{4}$. To do this, SIGIS (and other instruments that measure volcanic emissions) uses the radiation of the volcanic gas itself, allowing for continuous monitoring day and night of the volcanic plume (Stremme et al., 2012 and references therein). Compared to the E-AERI, some other ground-based infrared emission spectrometers used in the past, such as the Bruker IFS-120M and the Radiation Exolorer in the Far InfraRed-Prototype for Applications in Development (REFIR-PAD) (Becker and Notholt, 1997; Bianchini et al., 2010), have had a narrower spectral range but greater spectral resolution. For all these instruments, the spectra are calibrated using one or more blackbodies. Where one blackbody is used (such as with MIPAS-B), the instrument views cold space as the cold source and the blackbody as the hot source. Since the E-AERI cannot view cold space from the ground, it uses two blackbodies (ambient and hot) for its calibration. Regardless of the type of retrieval algorithm employed, atmospheric profiles of pressure and temperature from radiosondes are typically used as a priori input profiles. More information about the E-AERI (such as its field-of-view, nonlinearity knowledge, blackbody characterization, etc.) is provided in Table 2 of Mariani et al. (2012).

\subsection{SFIT2 emission add-on}

SFIT2 is a radiative transfer and profile retrieval algorithm based on the optimal estimation method (OEM) of Rodgers (1976, 1990, 2000). It produces a calculated spectrum that is fitted to an observed spectrum by adjusting the trace gas volume mixing ratio profiles (Pougatchev et al., 1995; Rinsland et al., 1998). The forward model is a multispecies, multilayer, line-by-line radiative transfer model. The model assumes the Voigt lineshape function, local thermodynamic equilibrium, and homogeneous layers of the atmosphere. SFIT2 is widely used in the infrared remote sounding community and has undergone extensive validation exercises (e.g. Hase et al., 2004). SFIT2 can be used in conjunction with FTIR spectra to retrieve more than 25 trace gases.

The SFIT2 retrieval code (along with its predecessors) was designed to use solar absorption measurements from an FTIR as input to the forward model. Hence modifications to the original SFIT2 (v. 3.93) code were required in order to adapt the algorithm to be used with emission spectra, such as those produced by the E-AERI. In this new emission add-on (SFIT2 v. 3.93 + Emission), the retrieval code has been modified with an extension to calculate the full radiative transfer. The radiative transfer is given by

$\frac{\mathrm{d} I}{\mathrm{~d} z}=-\alpha(z) \cdot(I-S)$,

where $\alpha$ denotes the absorption at a given altitude $(z), I$ denotes the radiance, and $S$ denotes the source term. Neglecting scattering, the source term, $S$, is given by Planck's function (expressed in $\mathrm{W} /\left[\mathrm{cm}^{2} \mathrm{srcm}^{-1}\right]$ ) for blackbody radiation:

$S=\frac{2 h c^{2} \tilde{v}^{3}}{e^{\left(\frac{h c \tilde{v}}{k_{\mathrm{B}} T}\right)}-1}$,

where $h$ denotes Planck's constant, $c$ denotes the speed of light, $k_{\mathrm{B}}$ denotes Boltzmann's constant, $T$ denotes the absolute temperature, and $\tilde{v}$ denotes the wavenumbers $\left(\mathrm{cm}^{-1}\right)$. In integral form, Eq. (1) is

$I(z)=S\left(z_{\infty}\right) e^{-\tau\left(0, z_{\infty}\right)}+\int_{\infty}^{0} S(z) \cdot \frac{\mathrm{d} e^{-\tau(0, z)}}{\mathrm{d} z} \mathrm{~d} z$,

where $\tau\left(0, z_{\infty}\right)$ denotes the opacity from the ground to the top of the atmosphere, $\tau(0, z)$ denotes the opacity from layer $z$ to the observer at $0, S\left(z_{\infty}\right)$ is the source term for the background (top of atmosphere) radiation, and $S(z)$ is the source term of the layer $z$. While in solar absorption spectroscopy, the rightmost term in Eq. (3) can normally be neglected (except for optically thick regions of the atmosphere) due to the negligible emission of the atmosphere compared to the sun, 
in emission spectroscopy this is the main source of radiation. The numerical iteration scheme used to find the zero of the gradient of the cost function in the OEM has also been changed from Gauss-Newton to Levenberg-Marquardt, which is more efficient in finding nonlinear solutions when the true solution is far from the current iteration point.

\subsection{Comparison datasets}

The Bruker 125HR FTIR spectrometer is a NDACC instrument that has been used to make solar-absorption measurements at the PEARL Ridge Lab since 2006 and has been compared with other datasets in several studies (Batchelor et al., 2009; Lindenmaier et al., 2010; Adams et al., 2012a). The 125HR provides partial and total column measurements of many trace gases during sun-lit months, including the four gases that can be measured by the E-AERI. The viewing geometry of the Bruker is a sun-pointing slant path. 125HR total column errors $\left(S_{\text {tot }}\right.$, comprising the smoothing error, measurement error, interference error, and forward model parameter error) are $4.3 \%$ for $\mathrm{O}_{3}, 1.8 \%$ for $\mathrm{CO}, 14.0 \%$ for $\mathrm{CH}_{4}$, and $3.9 \%$ for $\mathrm{N}_{2} \mathrm{O}$ (Lindenmaier, 2012), which are smaller than those of the E-AERI (10-15\%, as shown in Sect. 3.3).

The remaining solar-absorption spectrometers at PEARL have been involved in numerous validation campaigns and provide total columns of $\mathrm{O}_{3}$, and other trace gases. Three Environment Canada Brewer spectrophotometers (\#021, \#192, \#069) deployed on the roof of the PEARL Ridge Lab use direct and scattered sunlight at UV wavelengths (Savastiouk and McElroy, 2005). The viewing geometry of the Brewer spectrophotometers is a sun-pointing slant path, like the 125HR. The standard Brewer algorithm was used to analyse Brewer data, with small changes to the analysis parameters (e.g. the ozone layer was set at $18 \mathrm{~km}$ instead of $22 \mathrm{~km}$ to better reflect conditions in the Arctic) (Lam et al., 2007). The random error in Brewer total $\mathrm{O}_{3}$ measurements is typically less than 1\% (Savastiouk and McElroy, 2005).

The two UV-visible GBSs (both NDACC-certified) are very similar instruments and their measurements of zenithscattered sunlight were analysed using the same settings to retrieve $\mathrm{O}_{3}$ total columns (Fraser et al., 2009; Adams et al., 2012a,b). The two GBSs agree within $1 \%$ of each other and the total error of the $\mathrm{O}_{3}$ column is $6.2 \%$ (Adams et al., 2012a). An NDACC-certified SAOZ UV-visible grating spectrometer (Pommereau and Goutail, 1988) deployed on the roof of the PEARL Ridge Lab took zenith-sky measurements during the spring. The estimated error for SAOZ total $\mathrm{O}_{3}$ measurements is $5.9 \%$ (Hendrick et al., 2011). GBS and SAOZ total columns were retrieved independently, following NDACC guidelines, using the Differential Optical Absorption Spectroscopy (DOAS) technique (Platt and Stutz, 2008). Both the GBSs and SAOZ are zenith-viewing and use scattered sunlight at sunrise/sunset to make measurements pointing to the azimuth angle of the sun (which varies with the time of year).

\section{Methodology}

\subsection{Retrieval methodology}

In order to retrieve total columns of trace gases from E-AERI spectra, the SFIT2 retrieval algorithm is used in conjunction with the High Resolution Transmission Molecular Absorption Database (HITRAN) 2008 (Rothman et al., 2009). Refractive ray-tracing and air-mass path calculations are computed using the FASTCODE (also referred to as FSCATM) algorithm (Meier et al., 2004). With the OEM, the retrieved profile can be expressed as a linear combination of the a priori and the true state with error contributions. An independent wavelength shift parameter for each miniwindow and the background slope (any offset of the spectrum) are fitted. Due to the relatively low spectral resolution of the E-AERI, profile-scaled retrievals were performed (rather than full profile retrievals) in which the entire a priori profile of the trace gas is uniformly shifted (increased/decreased) by a scaling factor to match the true state. The scaled retrievals have degrees of freedom for signal just below $1(>0.9)$ per species and provide only the total column concentration. Attempts to perform retrievals on a multilayer grid resulted in convergence problems, likely due to the lack of vertical sensitivity in the lower-resolution E-AERI spectra.

The a priori volume mixing ratio (VMR) profiles for the target trace gas, a priori covariance matrix, $\mathbf{S}_{\mathrm{a}}$, and a priori interfering species VMR profiles are required inputs for the OEM. The a priori VMR profiles of the interfering species were scaled simultaneously with the target trace gas during the retrievals. SFIT2 can incorporate a maximum of nine interfering species for each miniwindow, which, in effect, places a limit on the maximum size of the miniwindow. While column retrievals are usually well constrained and need no regularization, the fact that columns of multiple species (target and interfering) are retrieved in one inversion adds instability which is remedied by the use of OEM. A priori estimates of trace gas VMR profiles at Eureka have been provided for 64 trace gases and used in previous studies involving SFIT2 retrievals (Batchelor et al., 2009; Lindenmaier et al., 2010). These profiles were produced from a climatology of satellite, ground-based, model, and balloon measurements. For the four gases studied in this work, over 7000 HALOE (Lat $>65^{\circ} \mathrm{N}$ ) profiles from 1991 to 2005 were used for $\mathrm{CH}_{4}$ (Park et al., 1996); the Eureka ozonesonde archive (1993-2005) and HALOE were used for $\mathrm{O}_{3}$ (averaged ozonesondes up to $35 \mathrm{~km}$ alt., HALOE $>35 \mathrm{~km}$ ) (Lindenmaier et al., 2010); MkIV balloon measurements made at the high-latitude NDACC site at Kiruna, Sweden, were used for $\mathrm{CO}$; and monthly mean VMRs reported in the SPARC2000 compilation (Lat $>68^{\circ} \mathrm{N}$ ) were used for $\mathrm{N}_{2} \mathrm{O}$ (Randel et al., 2002). The a priori profiles are zonally averaged mean VMR profiles of the climatological datasets (where latitude $>65^{\circ} \mathrm{N}$ ) available. For more detail about these climatologies, see Lindenmaier et al. (2012) (Sect. 3.4). 
Table 1. Retrieval specifications for each target trace gas: the retrieval miniwindow (spectral range), interfering species scale fitted in each miniwindow, SNR, and typical RMS residual of the spectral fit for spectra measured in December (June).

\begin{tabular}{lllll}
\hline $\begin{array}{l}\text { Trace } \\
\text { gas }\end{array}$ & $\begin{array}{l}\text { Miniwindow } \\
\left(\mathrm{cm}^{-1}\right)\end{array}$ & Interfering species & SNR & $\begin{array}{l}\text { Typical RMS } \\
\left(\mathrm{W} \mathrm{m}^{-2} \mathrm{srcm}^{-1}\right)\end{array}$ \\
\hline $\mathrm{O}_{3}$ & $950-1100$ & $\mathrm{H}_{2} \mathrm{O}, \mathrm{CO}_{2}, \mathrm{O}_{3}^{667}, \mathrm{O}_{3}^{676}, \mathrm{O}_{3}^{686}, \mathrm{O}_{3}^{668}$ & $40(80)$ & $2.7 \times 10^{-4}\left(5.9 \times 10^{-4}\right)$ \\
$\mathrm{CO}$ & $2000-2200$ & $\mathrm{O}_{3}, \mathrm{~N}_{2} \mathrm{O}, \mathrm{H}_{2} \mathrm{O}, \mathrm{OCS}$ & $50(200)$ & $9.9 \times 10^{-6}\left(4.6 \times 10^{-5}\right)$ \\
$\mathrm{CH}_{4}$ & $1150-1229$ & $\mathrm{SO}_{2}, \mathrm{H}_{2} \mathrm{O}, \mathrm{HDO}, \mathrm{O}_{3}, \mathrm{CCl}_{2} \mathrm{~F}_{2}, \mathrm{HNO}_{3}, \mathrm{CH}_{3} \mathrm{D}, \mathrm{N}_{2} \mathrm{O}$ & $40(90)$ & $2.3 \times 10^{-4}\left(6.5 \times 10^{-4}\right)$ \\
$\mathrm{N}_{2} \mathrm{O}$ & $1160-1300$ & $\mathrm{CH}_{4}, \mathrm{SO}_{2}, \mathrm{H}_{2} \mathrm{O}, \mathrm{HDO}, \mathrm{O}_{3}, \mathrm{CCl}_{2} \mathrm{~F}_{2}, \mathrm{HNO}_{3}, \mathrm{CH}_{3} \mathrm{D}$ & $35(110)$ & $3.3 \times 10^{-4}\left(6.9 \times 10^{-4}\right)$ \\
\hline
\end{tabular}

The diagonal elements of the a priori covariance matrix, $\mathbf{S}_{\mathrm{a}}$, which constrains the retrieval to the a priori, were calculated based on an uncertainty of $30 \%$ in the a priori VMR profile for each target gas; this value has been used for previous retrievals at Eureka as it represents the maximum tropospheric variability seen in the climatologies (Lindenmaier et al., 2012). A conservative estimate of $100 \%$ was used as the uncertainty in the a priori total columns of the interfering species, with the exception of $\mathrm{H}_{2} \mathrm{O}$, where it was set to $300 \%$ due to $\mathrm{H}_{2} \mathrm{O}$ 's large seasonal variability at Eureka. Daily profiles of pressure and temperature were obtained from a combination of three sources: two daily launches of radiosondes at Eureka were averaged to provide information up to $35 \mathrm{~km}$ above Eureka, the National Centre for Environmental Prediction (NCEP) analyses from the NASA Goddard Space Flight Centre provided information from 35 to $50 \mathrm{~km}$, and the 1976 US Standard Atmosphere was used above $50 \mathrm{~km}$.

An estimate of the instrument's noise is based on instrument root-mean-square (RMS) Noise Equivalent Spectral Radiance (NESR) tests performed by UW-SSEC (Mariani et al., 2012). The diagonals of the measurement noise covariance matrix, $\mathbf{S}_{\varepsilon}$, are equivalent to the noise ${ }^{2}$, where noise $=$ average of the NESR (which varies only slightly with wavenumber) throughout the miniwindow of the target trace gas. The signal-to-noise ratio (SNR) provides the ratio of the maximum emission (radiance) to the noise for the given miniwindow, and increases in the summer when the thermal emission is a maximum.

\subsection{Miniwindows}

Due to the lower spectral resolution of the E-AERI, the spectral regions that SFIT2 uses to fit the trace gas spectral lines must be significantly larger than those typically used in fitting high-resolution solar absorption spectra to incorporate sufficient spectral lines of the target trace gas. Since these fitted spectral regions are wider (10-25 times) than the standard microwindows used in NDACC IRWG SFIT2 retrievals, they will be referred to as "miniwindows". A comparison of possible miniwindows was performed for each target trace gas species in order to obtain the lowest fitted RMS residual while permitting retrieval convergence. Attempts were made to avoid spectral regions that have large $\mathrm{H}_{2} \mathrm{O}$ emission features due to their large variability and capacity to dwarf emission features of the target gas. The $\mathrm{H}_{2} \mathrm{O}$ continuum (resulting from numerous strong $\mathrm{H}_{2} \mathrm{O}$ lines up to $700 \mathrm{~cm}^{-1}$ ), in particular, was avoided as much as possible due to the difficulty in its characterization. Table 1 lists the miniwindow selected for each trace gas, the interfering species included in the retrieval, and the SNR (described in Sect. 3.1) and typical RMS residual in the spectral fit for the winter (December) and summer (June).

Examples of the spectral fits and residuals for each trace gas listed in Table 1 are shown in Fig. 2. A comparison between the fits in the summer (June) and winter (December) are provided using hourly averaged E-AERI spectra and are typical for these two seasons. The spectral fits change depending on the season; for instance, larger emission features are found in the summer compared to the winter due to the increased temperature (resulting in increased thermal emission) as well as other factors (e.g. strong $\mathrm{H}_{2} \mathrm{O}$ emission lines due to increased water vapour). Due to the difficulty in accurately fitting $\mathrm{H}_{2} \mathrm{O}$ spectral lines, this slightly increases the RMS residual in the summer months (May-August) and decreases the RMS residual in the winter months (NovemberFebruary). Meteorological events (i.e. ice clouds, fog, etc.) do not impact spectral fitting due to the cloud filtering performed prior to the SFIT2 retrievals (described in Sect. 2.1).

\subsection{Error analysis}

The uncertainty in the measured total columns is determined following the method described in Rodgers (2000), which has been demonstrated for the PEARL 125HR SFIT2 retrievals (Batchelor et al., 2009). Under this approach, the smoothing error, $S_{\mathrm{s}}$, and measurement error (referred to as covariance of the retrieval noise in Rodgers, 2000), $S_{\mathrm{m}}$, are added in quadrature with the forward model parameter errors and interference errors. The NESR, which quantifies the spectral noise, is $<0.4 \mathrm{~mW}\left(\mathrm{~m}^{2} \mathrm{srcm}^{-1}\right)^{-1}$ for $420-1400 \mathrm{~cm}^{-1}$ and $<0.015 \mathrm{~mW}\left(\mathrm{~m}^{2} \mathrm{srcm}^{-1}\right)^{-1}$ for $2000-$ $2600 \mathrm{~cm}^{-1}$. The radiometric calibration's absolute accuracy is $<1 \%$ of the ambient blackbody radiance. Forward model errors are determined using a perturbation method for temperature, $S_{\text {temp }}$, and the largest estimates of the uncertainties provided in HITRAN, $S_{\text {lint }}$ (line intensity) and $S_{\text {lwidth }}$ 


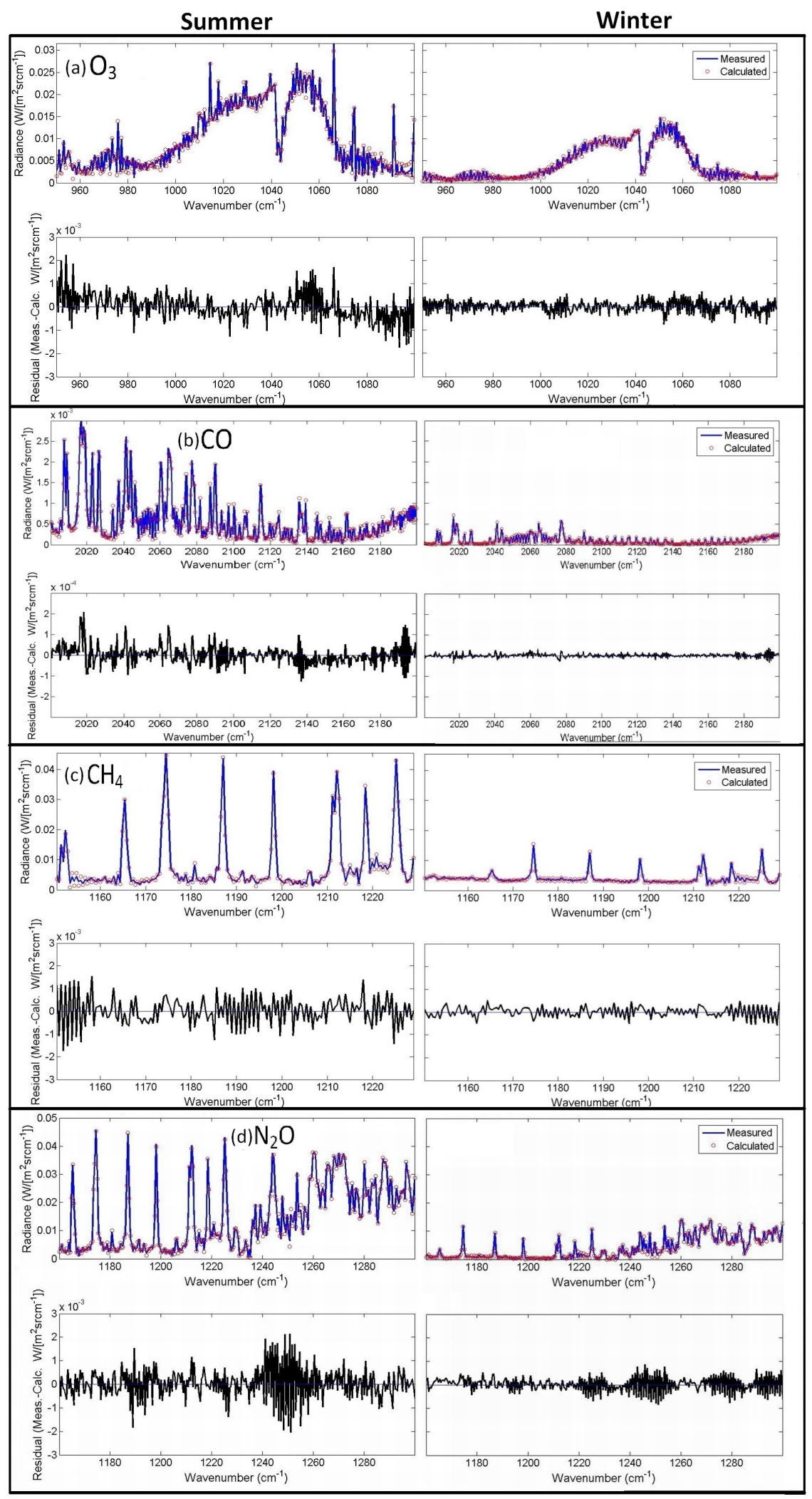

Fig. 2. Sample summer (29 June 2009; left column) and winter (31 December 2008; right column) of spectral fits for retrievals of (a) $\mathrm{O}_{3}$, (b) $\mathrm{CO}$, (c) $\mathrm{CH}_{4}$, and (d) $\mathrm{N}_{2} \mathrm{O}$. Top panels show the measured (blue) and fitted spectra (red circles), with their residuals shown in the bottom panels. Note the vertical scales are kept constant left-to-right while the residuals are on a finer scale. Retrievals were performed using SFIT2 and hourly averaged E-AERI spectra. 
Table 2. Error components for each retrieved trace gas total column. $S_{\text {tot }}$ is determined from Eq. (3). Errors are based on a single spectrum on 4 April 2009; these errors are typical for other dates and decrease slightly in the winter and increase slightly in the summer as a result of decreased/increased $\mathrm{H}_{2} \mathrm{O}$ emission (for instance).

\begin{tabular}{lcrcccccc}
\hline $\begin{array}{l}\text { Trace } \\
\text { gas }\end{array}$ & $\begin{array}{c}S_{\mathrm{m}} \\
(\%)\end{array}$ & $\begin{array}{r}S_{\mathrm{s}} \\
(\%)\end{array}$ & $\begin{array}{c}S_{\text {temp }} \\
(\%)\end{array}$ & $\begin{array}{c}S_{\text {lint }} \\
(\%)\end{array}$ & $\begin{array}{c}S_{\text {lwidth }} \\
(\%)\end{array}$ & $\begin{array}{c}S_{\text {intret }} \\
(\%)\end{array}$ & $\begin{array}{c}S_{\text {intspec }} \\
(\%)\end{array}$ & $\begin{array}{c}S_{\text {tot }} \\
(\%)\end{array}$ \\
\hline $\mathrm{O}_{3}$ & 1.1 & 6.1 & 8.7 & 2.9 & 0.5 & 0.01 & 1.4 & 11.3 \\
$\mathrm{CO}$ & 8.0 & 11.9 & 3.4 & 0.2 & 0.1 & 0.01 & 0.1 & 14.7 \\
$\mathrm{CH}_{4}$ & 6.0 & 8.2 & 3.3 & 2.2 & 0.4 & 0.01 & 0.2 & 11.0 \\
$\mathrm{~N}_{2} \mathrm{O}$ & 6.5 & 6.7 & 4.7 & 2.6 & 0.5 & 0.02 & 0.5 & 10.9 \\
\hline
\end{tabular}

(air-broadened half-width) (Rothman et al., 2009). A conservative estimate of $20 \%$ was used where the uncertainty in the line parameters was unknown (e.g. $\mathrm{O}_{3}$ line intensity). The maximum uncertainty within the quoted range from the radiosonde manufacturer (Vaisala) was used as the uncertainty associated with the atmospheric profiles of pressure $( \pm 1 \mathrm{hPa})$. In determining $S_{\text {temp }}$ via perturbation, the uncertainties provided in the NCEP profiles were used (a more conservative estimate of $2 \mathrm{~K}$ was used below $30 \mathrm{~km}, 5 \mathrm{~K}$ between 30 and $35 \mathrm{~km}, 6 \mathrm{~K}$ between 35 and $40 \mathrm{~km}, 7 \mathrm{~K}$ between 40 and $50 \mathrm{~km}$, and $9 \mathrm{~K}$ above $50 \mathrm{~km}$ ). The interference errors, $S_{\text {intspec }}$ and $S_{\text {intret }}$, are the errors in the retrieved column due to the constraint posed on the jointly retrieved quantities. The latter includes instrument lineshape, wavelength shift, background slope and curvature, phase error and zero level shift; their combination is described in Rodgers and Connor (2003). Since the E-AERI is zenith viewing, errors in the solar zenith angle $\left(S_{\mathrm{SZA}}\right)$ are zero. Hence the total error, $S_{\text {tot }}$, can be expressed as:

$S_{\mathrm{tot}}=\sqrt{S_{\mathrm{s}}^{2}+S_{\mathrm{m}}^{2}+S_{\mathrm{temp}}^{2}+S_{\text {lint }}^{2}+S_{\text {lwidth }}^{2}+S_{\text {intret }}^{2}+S_{\text {intspec }}^{2}} \cdot$

The uncertainty due to measurement noise $\left(S_{\mathrm{m}}\right)$ is considered to be random, and the uncertainty due to spectroscopic parameters ( $S_{\text {lint }}$ and $S_{\text {lwidth }}$ ) is mostly systematic, although a clear division between systematic and random uncertainties is not absolute. Since the different error sources are uncorrelated among each other, these errors have been added in quadrature, as recommended by the International Organization of Standardization (1993). Several error sources ( $S_{\text {intret }}$, $S_{\text {intspec }}, S_{\text {temp }}$, and $S_{\mathrm{s}}$ ) vary from spectrum to spectrum and can be season dependent. For instance, the interference from $\mathrm{H}_{2} \mathrm{O}$ line broadening decreases in the winter as the amount of water vapour in the troposphere decreases by over a factor of $>10$ (compared to the summer). For this reason, total errors are typically slightly smaller in the winter.

Thin clouds can result in doubling of the RMS residual in the spectral fits, reinforcing the requirement of the conservative cloud-filtering process. The impact of aerosols on the retrieval is similar (albeit smaller) and is discussed in more detail in Sect. 4. A perturbation method was used to assess the error associated with using the wrong a priori VMR profile shape of the target trace gas; VMR concentrations were perturbed $2 \%$ at one altitude grid and the change in the retrieved total column was calculated. The largest changes in the retrieved total column occur from perturbations to the lowermost altitudes of the troposphere, indicating that EAERI retrievals are dependent on the shape of the profile in the lower troposphere. This is discussed in more detail in Sect. 4. Table 2 lists the error components for each trace gas; retrievals performed on 4 April 2009 were used in the error analysis. The error bars in all graphs shown include all error sources $\left(S_{\text {tot }}\right)$. Further error characteristics of the E-AERI can be found in Table 2 of Mariani et al. (2012).

\section{2008-2009 trace gas measurements from the PEARL Ridge Lab}

\subsection{Comparisons of the E-AERI with other instruments}

Clear-sky total columns of $\mathrm{O}_{3}, \mathrm{CO}, \mathrm{CH}_{4}$, and $\mathrm{N}_{2} \mathrm{O}$ from the PEARL Ridge Lab were retrieved using hourly averaged E-AERI spectra (described in Sect. 2.1) and the SFIT2 emission add-on retrieval algorithm (described in Sects. 2.3, 3.1, and 3.2). These measurements at PEARL are not affected by local emissions of the Eureka weather station's power plant $15 \mathrm{~km}$ away. Figure 3 shows $\mathrm{O}_{3}, \mathrm{CO}, \mathrm{CH}_{4}$, and $\mathrm{N}_{2} \mathrm{O}$ total columns (from $0.610-100 \mathrm{~km}$ ) measured at the PEARL Ridge Lab between September 2008 and October 2009. Also shown are measurements from the Bruker 125HR, Brewer, GBSs, and SAOZ spectrometers. Error bars are shown only for the E-AERI total columns for clarity. The pressure-temperature profiles and a priori VMR profiles for the E-AERI and 125HR are the same and SFIT2 was used to perform the retrievals for both instruments, making their measurements ideal for comparison purposes. Different retrieval algorithms and techniques were used for the Brewer, GBS, and $\mathrm{SAOZ} \mathrm{O}_{3}$ retrievals, as discussed in Sect. 2.4.

To compare the E-AERI data with the $125 \mathrm{HR}$, a coincident time interval used the closest $125 \mathrm{HR}$ measurement recorded within $\pm 3 \mathrm{~h}$ of an E-AERI measurement to maximize the number of coincident data points while minimizing the effect of measuring different air masses. All of the E-AERI and 125HR $\mathrm{O}_{3}$ and $\mathrm{CH}_{4}$ total column measurements agree within combined E-AERI and 125HR errors. 

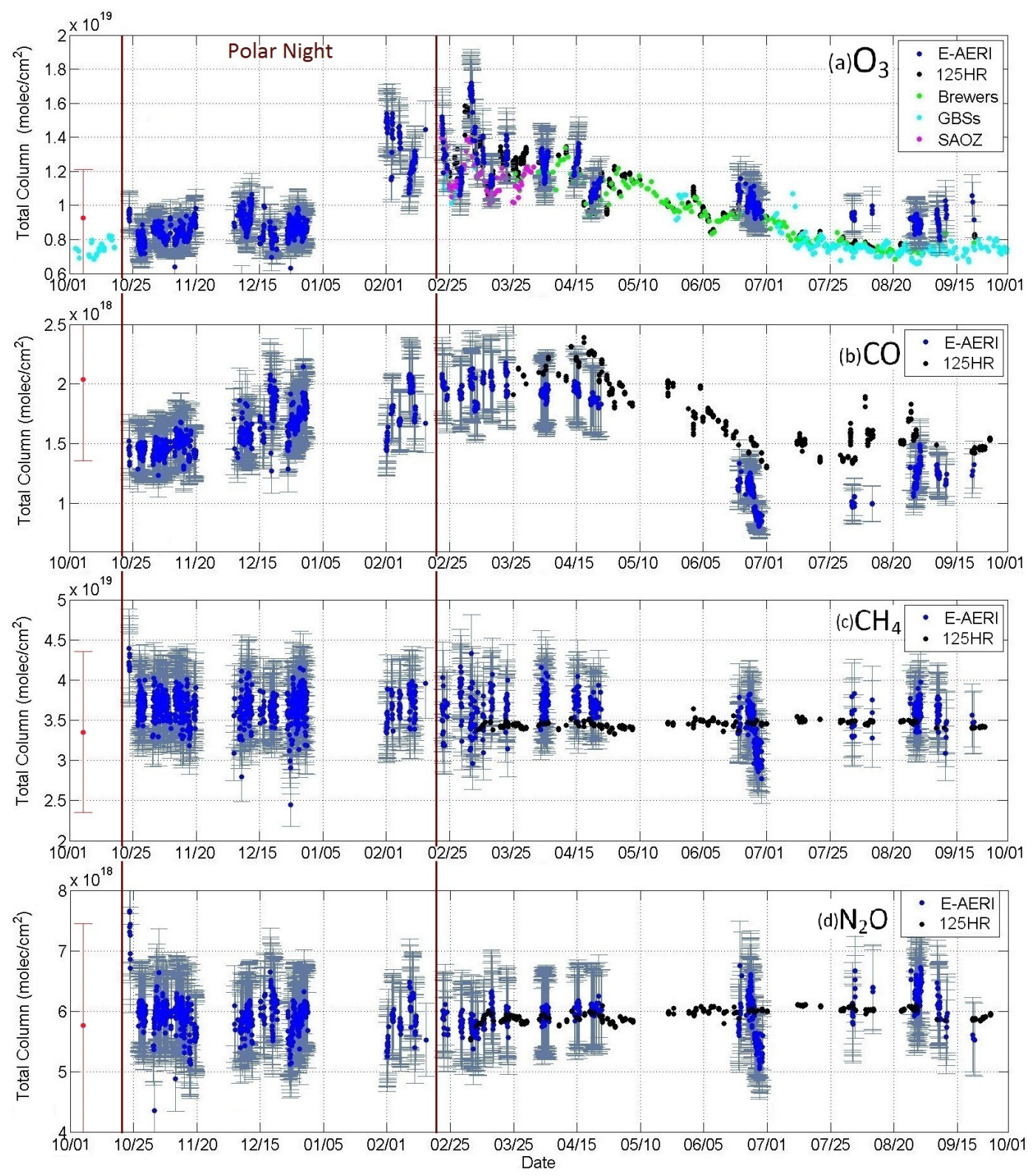

Fig. 3. Total column measurements of (a) $\mathrm{O}_{3}$, (b) $\mathrm{CO}$, (c) $\mathrm{CH}_{4}$, and (d) $\mathrm{N}_{2} \mathrm{O}$ from the PEARL Ridge Lab. Dates are given as MM/DD from 2008 to 2009. E-AERI (blue), 125HR (black), three Brewers (green), two GBSs (cyan), and the SAOZ (pink) measurements are shown for comparison. Error bars are shown only for the E-AERI for clarity. The a priori column is shown for one day (red) with error bars corresponding to the diagonal of $\mathbf{S}_{\mathrm{a}}$. Polar night is indicated between the brown vertical lines.

For $\mathrm{N}_{2} \mathrm{O}$ and $\mathrm{CO}$, the agreement is slightly worse; 93 and $90 \%$ of the measurements, respectively, agree within combined errors. Comparisons between the two instruments can be quantified using the mean relative difference, which is the mean of the difference between the two instruments' measurements divided by their average, and the standard error on the mean, $(\sigma / \sqrt{N}$, where $\sigma=$ standard deviation and $N=$ number of data points). The mean relative differences $(100 \% \times[$ E-AERI - instrument $] /$ mean $)$ between the E-AERI and the 125HR, Brewers, GBSs, and SAOZ are provided in Table 3. These differences are smaller than the total uncertainties $\left(S_{\text {tot }}\right)$ of the E-AERI total column measurements reported in Table 2, indicating good agreement. When the random error, $S_{\mathrm{m}}$, is removed from $S_{\text {tot }}$, the differences are smaller than the uncertainty for all trace gases except CO. To account for differences in vertical sensitivity between the E-AERI and 125HR, their averaging kernels must be considered. A typical February E-AERI total column averaging kernel, which was calculated using a perturbation method, is compared to a typical February 125HR averaging 
Table 3. $\mathrm{O}_{3}, \mathrm{CO}, \mathrm{CH}_{4}$, and $\mathrm{N}_{2} \mathrm{O}$ total column comparisons between the E-AERI and the $125 \mathrm{HR}$ (both unsmoothed and smoothed by the monthly E-AERI averaging kernels), Brewers, GBSs, and SAOZ for 2008-2009 and 2011. The Brewers, GBSs, and SAOZ cannot measure $\mathrm{CO}, \mathrm{CH}_{4}$, and $\mathrm{N}_{2} \mathrm{O}$. The mean relative difference $(100 \% \times[\mathrm{E}-\mathrm{AERI}-$ instrument $] /$ mean $)$ is given with the standard error $(\sigma / \sqrt{ } N)$ and the number of coincident data points $(N)$ in brackets.

\begin{tabular}{llrrlll}
\hline & & \multicolumn{5}{c}{ Mean relative difference with the E-AERI (\%) } \\
\cline { 3 - 7 } Year & Trace & $\begin{array}{r}125 \mathrm{HR} \\
\text { gas }\end{array}$ & $\begin{array}{r}\text { 125HR } \\
\text { smomoothed }\end{array}$ & Brewers & GBSs & SAOZ \\
\hline $2008-$ & $\mathrm{O}_{3}$ & $7.7 \pm 0.3(437)$ & $4.0 \pm 0.3(437)$ & $9.9 \pm 1.6(137)$ & $-2.9 \pm 1.0(222)$ & $8.4 \pm 0.9(188)$ \\
2009 & $\mathrm{CO}$ & $-14.4 \pm 1.4(366)$ & $-8.7 \pm 1.3(366)$ & - & - & - \\
& $\mathrm{CH}_{4}$ & $2.0 \pm 0.3(474)$ & $1.7 \pm 0.3(474)$ & - & - & - \\
& $\mathrm{N}_{2} \mathrm{O}$ & $-1.2 \pm 0.4(514)$ & $-1.0 \pm 0.4(514)$ & - & - & - \\
\hline 2011 & $\mathrm{O}_{3}$ & $8.1 \pm 1.0(123)$ & $5.5 \pm 0.9(123)$ & N/A (0) & $-9.4 \pm 1.2(27)$ & $7.4 \pm 1.9(144)$ \\
& $\mathrm{CO}$ & $-1.9 \pm 0.6(4)$ & $-0.9 \pm 0.6(4)$ & - & - & - \\
& $\mathrm{CH}_{4}$ & $-1.2 \pm 1.4(144)$ & $-0.8 \pm 1.3(144)$ & - & - & - \\
& $\mathrm{N}_{2} \mathrm{O}$ & $-2.1 \pm 0.9(132)$ & $-1.5 \pm 0.8(132)$ & - & - & - \\
\hline
\end{tabular}
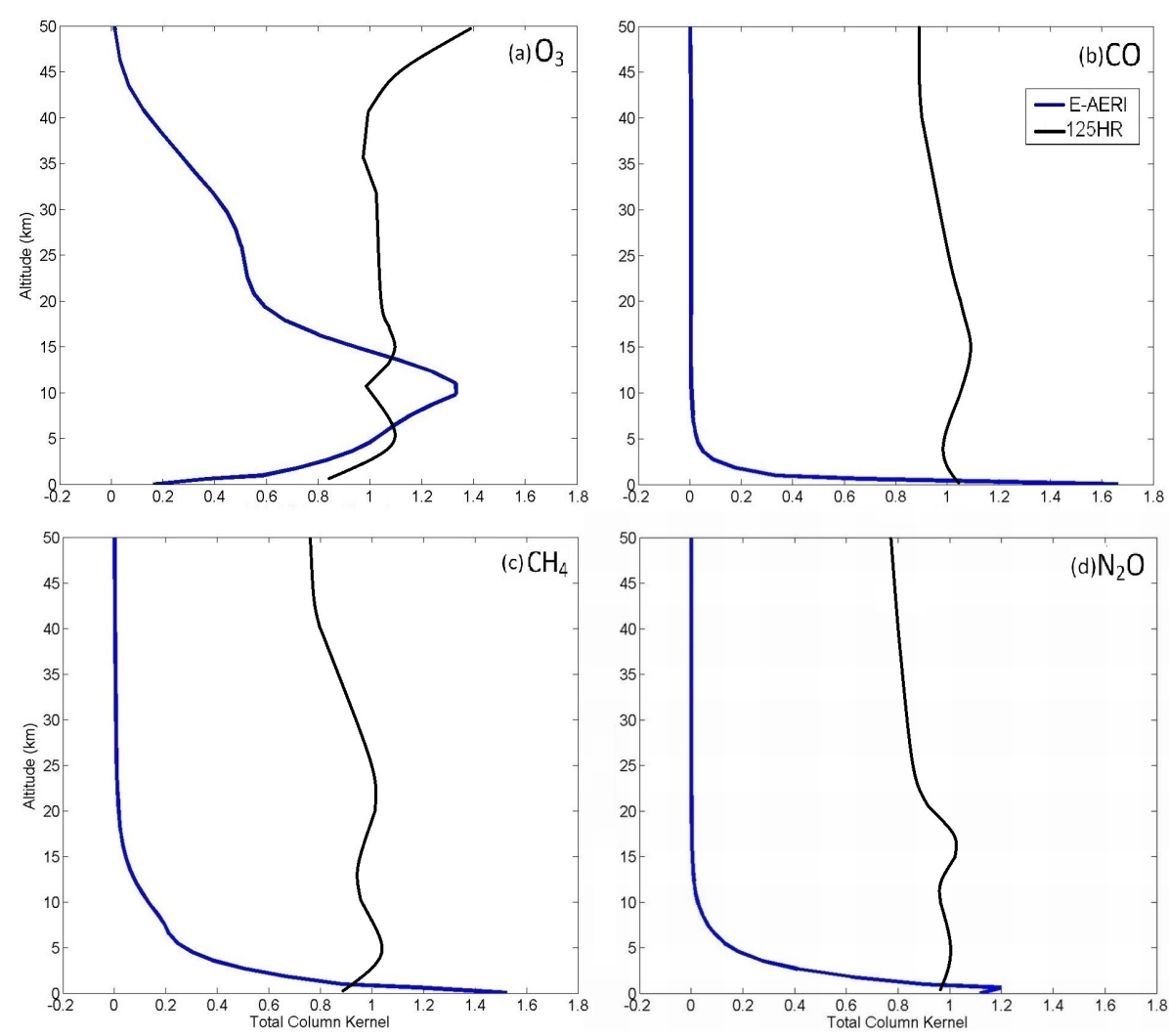

Fig. 4. Typical E-AERI (blue) and $125 \mathrm{HR}$ (black) total column averaging kernels (molec $\mathrm{cm}^{-2} / \mathrm{molec}^{-2}$ ) in February for (a) $\mathrm{O}_{3}$, (b) $\mathrm{CO}$, (c) $\mathrm{CH}_{4}$, (d) $\mathrm{N}_{2} \mathrm{O}$.

kernel in Fig. 4. Using these averaging kernels, the 125HR profiles can be smoothed by the monthly E-AERI averaging kernels to produce smoothed 125HR total columns (from the smoothed profile). The smoothed measurement represents the profile the $125 \mathrm{HR}$ would measure if it had the same resolution and vertical sensitivity as the E-AERI, and is computed using Eq. (4) of Rodgers and Connor (2003). After smoothing, the differences shown in Table 3 between the E-AERI and 125HR are less, particularly for $\mathrm{O}_{3}$ and $\mathrm{CO}$. Note the smoothed measurements are not shown in Fig. 3 for clarity.

The larger difference for $\mathrm{CO}$ total columns is comparable to the differences (up to $17 \%$ ) found between AERI CO retrievals and convolved in situ $\mathrm{CO}$ measurements by Yurganov 
et al. (2010), who attribute these discrepancies to the effect of aerosols on the measured radiances, which is not accounted for in their retrieval (nor in SFIT2). The largest differences seen in Fig. 3 occur in the summer months and are likely the result of increased $\mathrm{H}_{2} \mathrm{O}$ and scattered solar energy from aerosols during this season. If the aerosol diameter is smaller than the wavelength (roughly), scattering can be neglected and the effect in the emission spectrum is primarily that of a broad emission feature in the spectra. Only for larger aerosols does scattering become important. $\mathrm{As}_{2} \mathrm{O}$ increases in the atmosphere, the intensity of $\mathrm{H}_{2} \mathrm{O}$ emission lines increase, which makes them appear broader. The strong $\mathrm{H}_{2} \mathrm{O}$ spectral lines dominate and interfere with the neighbouring spectral lines of the target trace gas, increasing the difficulty of distinguishing the emission signature of $\mathrm{H}_{2} \mathrm{O}$ from that of the target trace gas. As a result, the $\mathrm{H}_{2} \mathrm{O}$ concentration is overestimated while the $\mathrm{CO}$ concentration is under-estimated for E-AERI CO retrievals in the summer. This is compounded by scattered solar energy from aerosols, which are not accounted for in SFIT2 and only have an impact in the summer months due to increased scattering via a higher solar elevation angle and increased aerosol particle size.

The seasonal cycle of $\mathrm{O}_{3}$ (maximum in the late winter), driven by the Brewer-Dobson circulation, can be seen by the E-AERI, as is evident in Fig. 3. In addition, like the other spectrometers, the E-AERI observes a decrease in $\mathrm{O}_{3}$ beginning in late February, which occurs as sunlight returns to Eureka. The seasonal cycle of $\mathrm{CO}$ (maximum in the winter) can also be observed, as previously demonstrated in Yurganov et al. (2010). Additional variation in the CO total column may be due to transport of biomass burning plumes and industrial emissions from lower latitudes to the Arctic (Stohl, 2006), with $\mathrm{CO}$ accumulating during the winter in the absence of $\mathrm{OH}$ oxidation. While most biomass burning events occur in the summer, dynamical transport from northern Eurasia into the polar dome occurs during the winter when only the E-AERI is operating (Stohl, 2006). On average, E-AERI measurements of $\mathrm{CH}_{4}$ and $\mathrm{N}_{2} \mathrm{O}$ remain relatively constant throughout the year, as expected, yet individually they are more variable than those measured with the 125HR (although not significantly given the timescales). This is likely due to the E-AERI being over-sensitive to the surface concentration, whereas the contribution of the surface concentration in the $125 \mathrm{HR}$ total column is diluted since the $125 \mathrm{HR}$ has greater vertical sensitivity which includes the stratosphere as shown in Fig. 4.

There are two key differences between the E-AERI and the other ground-based spectrometers' measurements that can also contribute to the differences in Fig. 3. First, the E-AERI is zenith viewing and samples air directly above PEARL, whereas the other spectrometers have different viewing geometries (as discussed in Sect. 2.4). Second, since the EAERI measures thermal infrared emission, a sensitivity analysis indicates measured radiances are highly sensitive to the lower troposphere. This is also indicated in Mariani et al. (2012) and is evident in the seasonal cycle characteristic of tropospheric CO, as seen in Fig. 3. The other spectrometers are more sensitive to the stratosphere and thus to changes in the stratospheric concentration - for example, changes associated with chemical $\mathrm{O}_{3}$ depletion. The E-AERI profilescaled retrievals scale uniformly throughout the entire profile (the shape of the a priori profile cannot be altered), however, and are biased towards the concentration in the troposphere, contributing to the observed discrepancies.

The E-AERI and $125 \mathrm{HR} \mathrm{O}_{3}$ and $\mathrm{CO}$ measurements are highly correlated, as shown in Fig. 5, with a correlation coefficient of 0.92 and 0.95 , respectively (unsmoothed). As with the mean relative difference comparisons, $\mathrm{a} \pm 3 \mathrm{~h}$ time interval was used to identify coincident measurements. Smoothed 125HR columns shown in Fig. 5 result in stronger correlations, particularly for $\mathrm{CO}$, as expected. E-AERI and Brewer, GBS, and $\mathrm{SAOZ} \mathrm{O}_{3}$ correlations (not shown) are not as strong ( $r=0.70,0.71$, and 0.61 , respectively), but given the different measurement techniques, this is expected. E-AERI and $125 \mathrm{HR} \mathrm{CH}_{4}$ and $\mathrm{N}_{2} \mathrm{O}$ measurements are poorly correlated due to the lack of seasonal variability giving little dynamic range (not shown). E-AERI $\mathrm{O}_{3}$ columns are typically greater than those measured by the $125 \mathrm{HR}$ by $7 \%$ (averaged year-round), or by as much as $8-12 \%$ in the summer. E-AERI CO columns are systematically smaller than those of the 125HR with a systematic bias of approximately $-14 \%$ (for unsmoothed columns averaged year-round), or by as much as $10-27 \%$ in the summer. This bias accounts for the observed offset in the linear fit shown in Fig. 5b, which is very similar to the bias in the AERI vs. vertically averaged convolved in situ CO measurements $(\sim 13 \%)$ in Yurganov et al. (2010), which has a comparable correlation $(m=0.92$, $r=0.76$ ). Since the mean relative error is larger than the error on that mean (i.e. larger than $3 \sigma / \sqrt{ } N$ ), the bias is statistically significant (Vigouroux et al., 2007). This indicates $\mathrm{CO}$ measurements from AERI instruments in general exhibit a systematic low bias compared to in situ and other remote sensing instruments.

\subsection{Diurnal and seasonal cycles of $\mathrm{CO}$}

The ability of AERI systems to measure the seasonal and $24 \mathrm{~h}$ diurnal cycle of $\mathrm{CO}$ was demonstrated in Yurganov et al. (2010). The total column of CO is at a minimum during sun-lit hours and a maximum during the night due to dynamical transport and $\mathrm{OH}$ oxidation of $\mathrm{CO}$, where $\mathrm{OH}$ is produced via photolysis. The $24 \mathrm{~h}$ diurnal cycle of $\mathrm{CO}$ for the entire year and for three different seasons experienced in the high Arctic can be seen in Fig. 6. The $24 \mathrm{~h}$ cycle of CO total column during polar night (22 October to 19 February) is compared to the $24 \mathrm{~h}$ cycle during polar day (22 April to $20 \mathrm{Au}-$ gust) and the $24 \mathrm{~h}$ cycle during "equinoctial" months (March and September), which have roughly equal hours of sun and night in each day. As observed in the full year and equinoctial panels a and d, CO has a maximum around midnight as 

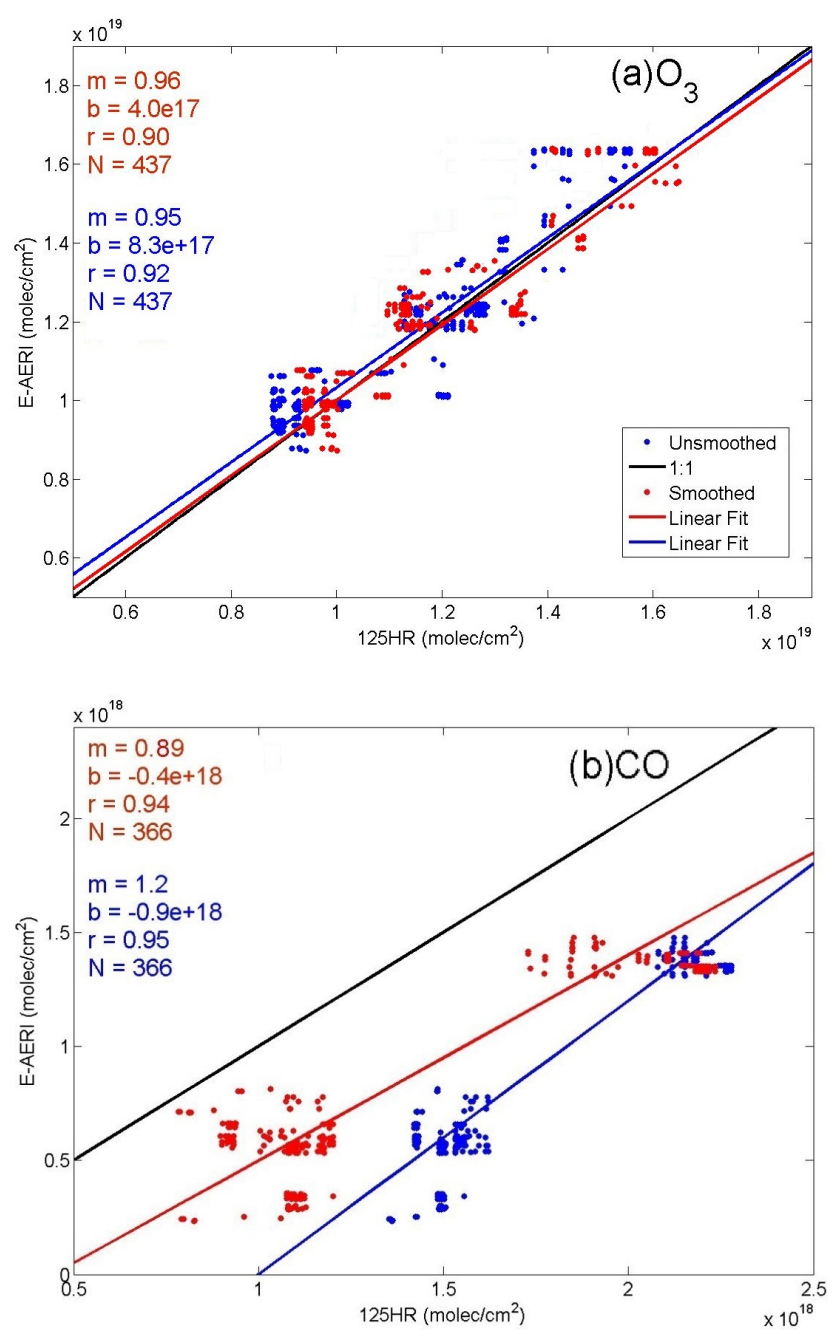

Fig. 5. Total column comparisons for E-AERI vs. $125 \mathrm{HR}$ (a) $\mathrm{O}_{3}$ and (b) $\mathrm{CO}$ using a $\pm 3 \mathrm{~h}$ coincidence criterion. The black line indicates the 1-1 line, the red and blue lines indicate the linear fit $(m$ is the fitted slope, $b$ is the fitted y-intercept, $r$ is the Pearson productmoment correlation coefficient, $N$ is the number of coincidences). $125 \mathrm{HR}$ total columns smoothed by the monthly E-AERI averaging kernel (Fig. 4) are shown in red.

expected. The $24 \mathrm{~h}$ diurnal cycle has an amplitude (maximum $\mathrm{CO}$ at night-minimum $\mathrm{CO}$ during the day/mean) of $\sim 6 \%$ (indicated in panel a) for the full year; this is enhanced to $\sim 12 \%$ (indicated in panel d) when filtered for the equinoctial months. Although the $24 \mathrm{~h}$ equinoctial cycle is more variable (larger error bars are due to the larger standard deviation), the amplitude is enhanced as expected, as this is the only time the Arctic receives roughly $12 \mathrm{~h}$ of sunlight each day. Note that more measurements were obtained during the polar night and equinoctial months compared to polar day, which has the adverse effect of biasing the full-year results. These amplitudes $(\sim 6$ and $\sim 12 \%)$ are in good agreement with the $\sim 8 \%$ amplitude in the $24 \mathrm{~h}$ diurnal cycle of $\mathrm{CO}$ in
Oklahoma found in Yurganov et al. (2010) and are the first measurements of this kind at Eureka.

The average $\mathrm{CO}$ total column during the equinoctial months is greater than the average $\mathrm{CO}$ during polar night due to the lifetime of $\mathrm{CO}(\sim 2$ months $)$. Almost all measurements during the equinoctial period were taken in March, when the concentration of $\mathrm{CO}$ is at a maximum (as indicated in Fig. 3). Despite the sun's return in February, $\mathrm{CO}$ was built up during the polar night and a lag between the sun's return, and the depletion of $\mathrm{CO}$ due to $\mathrm{OH}$ oxidation occurs, resulting in the maximum occurring in March. Note that in order to quantify the impact of $\mathrm{OH}$ oxidation, the contribution from scattered solar energy by aerosols in the summer, which has a larger signature in the $\mathrm{CO}$ miniwindow, will have to be removed (future work).

The amplitude of the 365-day seasonal cycle of $\mathrm{CO}$ is much larger than the $24 \mathrm{~h}$ diurnal cycle. From Fig. 3, the amplitude of the seasonal cycle of $\mathrm{CO}$ is $\sim 57 \%$ (maximum $\mathrm{CO}$ in March - minimum CO in July/mean). As shown in Fig. 6, $\mathrm{CO}$ columns during polar day are $\sim 46 \%$ lower (indicated in panel c) than during polar night on average, consistent with the $24 \mathrm{~h} \mathrm{OH}$ oxidation in the summer. These are the first measurements of the 365-day seasonal cycle of $\mathrm{CO}$ in the high Arctic performed by an FTIR. Both of these amplitudes are larger than that in Oklahoma ( $\sim 40 \%)$ (Yurganov et al., 2010), indicating a stronger 365-day seasonal cycle of CO at Eureka compared to mid-latitudes. Given the $24 \mathrm{~h}$ darkness followed by $24 \mathrm{~h}$ sunlight experienced in the Arctic, the increase in the amplitude of the 365-day seasonal cycle of $\mathrm{CO}$ is expected; however, given the larger bias of E-AERI CO vs. 125HR CO in the summer, seen in Fig. 3, this seasonal cycle may be over-estimated.

\section{1 trace gas measurements from OPAL}

Starting on 16 February 2011, the E-AERI resumed measurements closer to sea level at OPAL. The $600 \mathrm{~m}$ difference between the two sites has a large impact on the measured radiance, such as differences in the $\mathrm{CO}_{2}$ band between 600 and $800 \mathrm{~cm}^{-1}$ due to a temperature inversion and - most notably $-\mathrm{H}_{2} \mathrm{O}$ saturation (Mariani et al., 2012). Increased occurrence of clouds at lower altitudes also results in more spectra being excluded due to cloud filtering. Depending on the season, $10-20 \%$ of the water vapour column is located below $610 \mathrm{~m}$, increasing the amount of $\mathrm{H}_{2} \mathrm{O}$ interference with the target trace gas. Retrievals were performed using a total column from 0.010 to $100 \mathrm{~km}$. To perform comparisons with total column measurements made from the PEARL Ridge Lab, the first $600 \mathrm{~m}$ of the E-AERI total columns were removed (the scaled VMR profile is on a 39 layer altitude grid; the lowest of which is $0.010-0.610 \mathrm{~km}$ ) to match them with those measured at the Ridge Lab, effectively providing $0.610-100 \mathrm{~km}$ total columns. The additional error due to this removal is small ( $<1 \%$ for $\mathrm{O}_{3}$ and $<2 \%$ for the tropospheric species). 


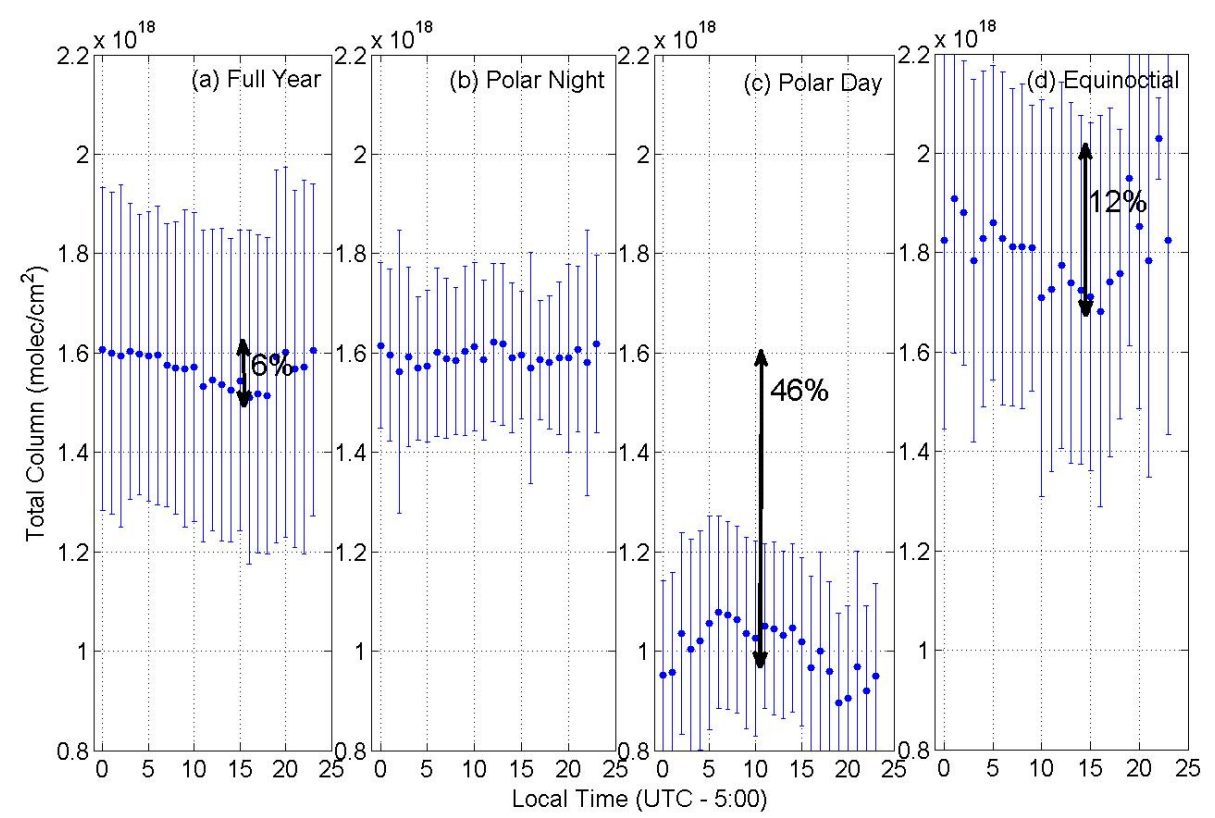

Fig. 6. $24 \mathrm{~h}$ diurnal cycle of CO during each season as measured by the E-AERI during 2008-2009: (a) averaged across the full year, (b) averaged during polar night (no sun), (c) averaged during polar day (only sun), and (d) March and September averaged during $\sim 12 \mathrm{~h}$ of sunlight (equinoctial). Error bars represent the standard deviation of the hourly means.

Figure 7 shows measurements of total columns in 2011 of the same four trace gases shown in Fig. 3. Large gaps in the E-AERI data record are discussed in Sect. 2.1. The EAERI total columns from OPAL exhibit similar behaviour to those measured two years prior at the PEARL Ridge Lab, despite the additional water vapour. For instance, the seasonal cycle of $\mathrm{CO}$ can be resolved and the E-AERI $\mathrm{CH}_{4}$ and $\mathrm{N}_{2} \mathrm{O}$ total columns exhibit larger variability than the $125 \mathrm{HR}$ measurements, particularly in the summer. Persistent polar stratospheric clouds within the polar vortex resulted in severe chemical $\mathrm{O}_{3}$ loss over Eureka in February and March 2011 (Manney et al., 2011; Adams et al., 2012b; Lindenmaier et al., 2012). This $\mathrm{O}_{3}$ loss is observed by the E-AERI, although not to the same magnitude (due to the difference in vertical sensitivity). $\mathrm{O}_{3}$ columns a week prior to the start of solar absorption measurements in 2011 are available from the EAERI. All of the E-AERI $\mathrm{O}_{3}, \mathrm{CO}$, and $\mathrm{CH}_{4}$ total columns agree within error with the $125 \mathrm{HR}$ measurements ( $96 \%$ for $\mathrm{N}_{2} \mathrm{O}$ ).

The mean relative differences between the E-AERI and 125HR, Brewers, GBSs, and SAOZ for both 2008-2009 and 2011 are provided in Table 3. All mean relative differences are less than the uncertainties in the respective E-AERI total columns (see Table 2). Note that although the general agreement in 2011 is better than in 2008-2009, the number of coincident measurements is significantly smaller for all trace gases, with almost no coincident measurements occurring in the summer, where the largest discrepancies were observed in the 2008-2009 comparisons. Few $(N=27)$ coincident measurements between the E-AERI and the GBSs existed in 2011 (and no coincidences with the Brewers), likely attributing to worse agreement for $\mathrm{O}_{3}$ than in 2008-2009. The E-AERI $\mathrm{O}_{3}$ measurements consistently have a positive bias compared to the $125 \mathrm{HR}$, Brewers, and SAOZ throughout both measurement periods (2008-2009 and 2011), which is most prominent in the summer months (as with the 20082009 PEARL E-AERI retrievals). A negative bias relative to the GBSs is observed throughout both measurement periods, with very good agreement in 2008-2009.

As seen in Fig. 8, 2011 E-AERI and $125 \mathrm{HR} \mathrm{O}_{3}$ total column measurements are well correlated $(r=0.72$ for smoothed 125HR columns), with weaker correlations between the E-AERI and the GBSs and SAOZ $(r=0.43$ and 0.65 , respectively, unsmoothed). There were no coincident measurements between the E-AERI and Brewers during 2011. While the correlations are not as strong as for the 2008-2009 measurements from the PEARL Ridge Lab, this is likely due to the increase of aerosols at lower altitude (which is not accounted for in SFIT2), a smaller seasonal sampling range, and fewer coincident measurements in 2011 than for 2008-2009. The apparent positive bias for $\mathrm{CH}_{4}$ and $\mathrm{N}_{2} \mathrm{O}$ total columns in summer 2011 compared to summer 2008-2009 is likely due to the enhanced influence that increased aerosols and water vapour concentrations have on the retrievals for lower measurement altitudes (OPAL vs. PEARL). As in 2008-2009, E-AERI O 3 columns are typically greater than the 125HR's (up to $5 \%$ ). $125 \mathrm{HR}$ CO measurements did not commence until later in the spring, when the E-AERI was not operating. For this reason, there were too few coincidences $(N=4)$ between the E-AERI and 125HR 


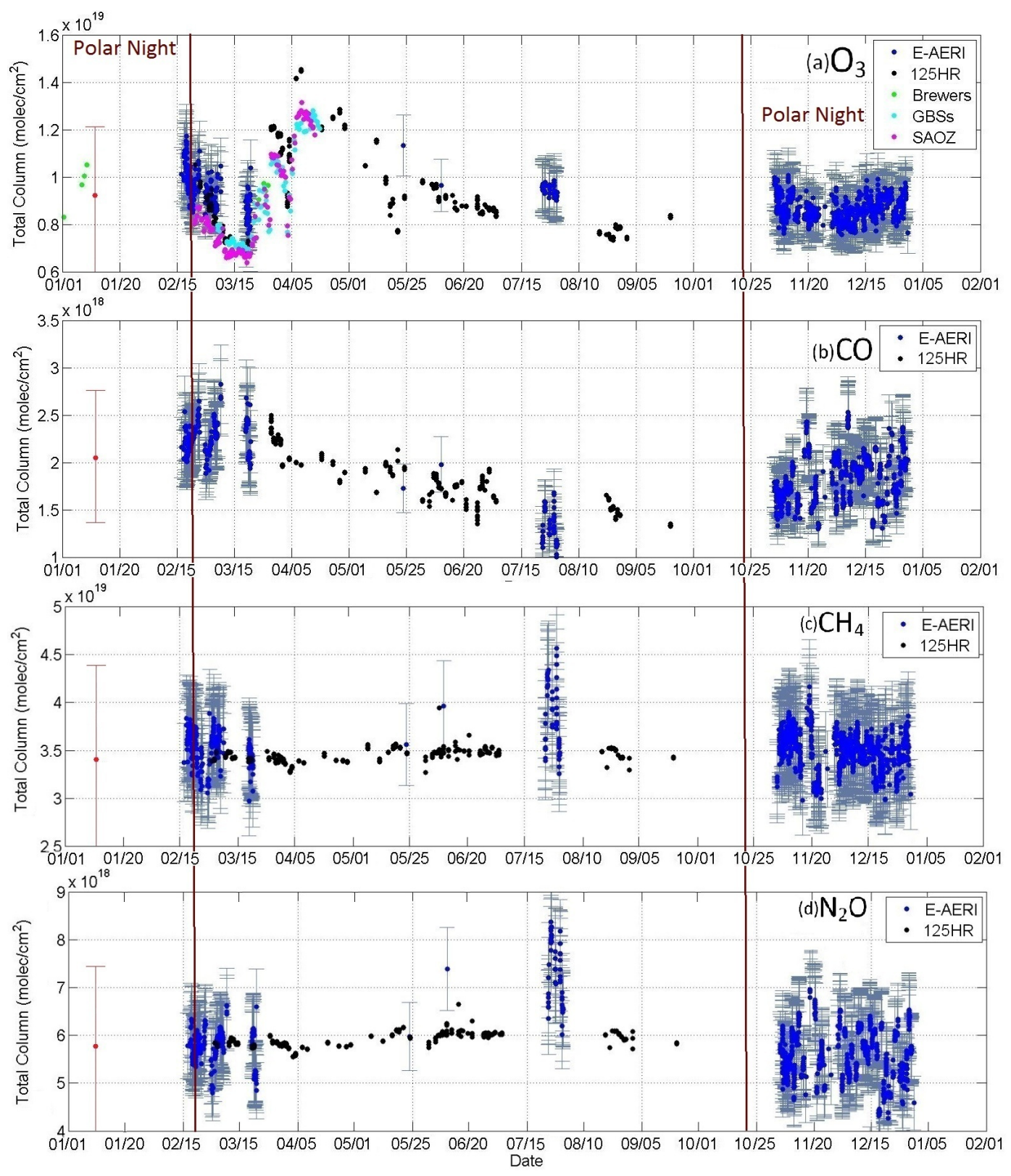

Fig. 7. Same as in Fig. 3, except for 2011. The E-AERI was located at OPAL (10 m altitude) and retrieved total columns are from 0.61 to $100 \mathrm{~km}$, while the other spectrometers were located at the PEARL Ridge Lab (610 m altitude). The a priori column is shown for one day (red) with error bars corresponding to the diagonal of $\mathbf{S}_{\mathrm{a}}$. Polar night is indicated outside the brown vertical lines.

to accurately determine their $\mathrm{CO}$ correlation. $\mathrm{CH}_{4}$ and $\mathrm{N}_{2} \mathrm{O}$ measurements are poorly correlated due to the lack of seasonal variability (not shown). Despite the additional water vapour at OPAL, based on the results in Table 3, E-AERI trace gas retrievals are comparable to those obtained at the PEARL Ridge Lab.

\section{Conclusions}

Total columns of $\mathrm{O}_{3}, \mathrm{CO}, \mathrm{CH}_{4}$, and $\mathrm{N}_{2} \mathrm{O}$ have been retrieved from October 2008 to September 2009 throughout polar night at the PEARL Ridge Lab and from February to December 2011 at OPAL using a new version of the SFIT2 retrieval algorithm adapted for infrared emission spectra. This is the first time infrared emission spectra have been used to retrieve trace gases using the newly modified version of SFIT2. The retrieval methodology described in this paper can be extended to all AERI instruments (of which more than 25 


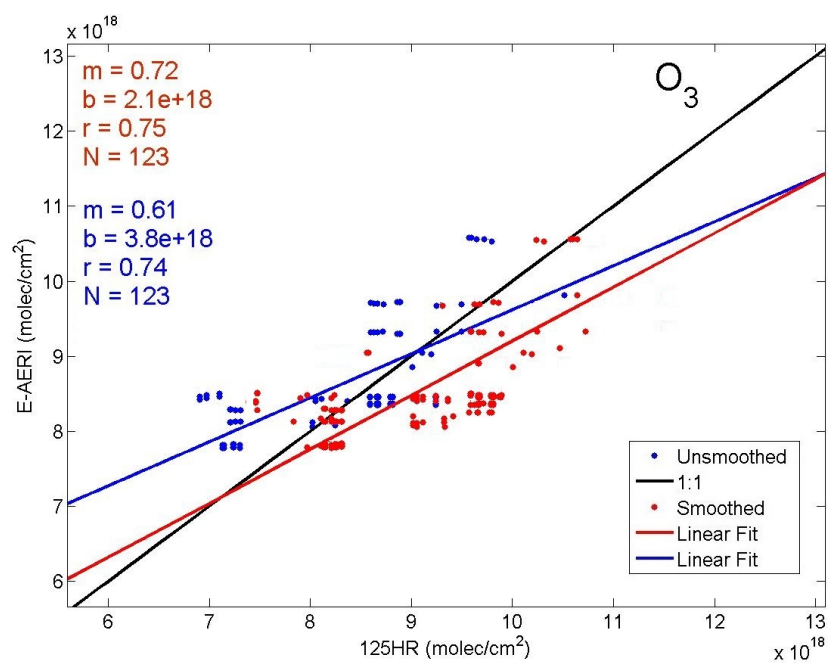

Fig. 8. Same as Fig. 5, but for $2011 \mathrm{O}_{3}$ total column comparisons for E-AERI vs. $125 \mathrm{HR}$ using a $\pm 3 \mathrm{~h}$ coincidence criterion.

are in operation across the globe) and other spectrometers that measure infrared emission. This paper has also presented the first continuous ground-based polar night trace gas measurements at Eureka, which fill a gap in the PEARL dataset when the solar-viewing spectrometers are not operating. Obtaining continuous measurements of trace gases throughout polar night is valuable for long-term climatological studies of various trace gases as well as the determination of their seasonal variability.

Spectral fits indicate that SFIT2 is capable of accurately fitting the observed spectra, with RMS residuals consistent with the NESR level. The performance of the spectral fits is equivalent at $\mathrm{PAL}$, where there is $10-20 \%$ more water vapour. An error analysis has been performed, indicating that the uncertainty in the E-AERI total column measurements is $11.3 \%$ for $\mathrm{O}_{3}, 14.7 \%$ for $\mathrm{CO}, 11.0 \%$ for $\mathrm{CH}_{4}$, and $10.9 \%$ for $\mathrm{N}_{2} \mathrm{O}$. E-AERI trace gas measurements agree well with those from the other spectrometers: mean relative differences are less than the uncertainties in the E-AERI total columns ( 1 to $10 \%$ differences). The 2008-2009 E-AERI and $125 \mathrm{HR}$ measurements of $\mathrm{O}_{3}$ and $\mathrm{CO}$ are highly correlated, with a correlation coefficient of $r=0.92$ and 0.95 , respectively, which is stronger than the $\mathrm{O}_{3}$ correlations with the other spectrometers. The 2011 E-AERI OPAL retrievals are comparable to those of 2008-2009, despite the increased water vapour at OPAL. The E-AERI vs. 125HR CO correlation is comparable to the AERI vs. convolved in situ CO correlation ( $m=0.92, r=0.76)$ found in Yurganov et al. (2010). The largest differences between the E-AERI and the other spectrometers for all four gases occur in the summer, indicating that the accuracy of the E-AERI's retrievals is season dependent. This is likely due to the large $(\sim 10 \times)$ seasonal variability of water vapour in the high Arctic and scattered solar energy by aerosols in the summer which is not accounted for in SFIT2.

The budget of $\mathrm{O}_{3}$ prior to, during, and after $\mathrm{O}_{3}$ depletion events can be determined using E-AERI measurements. The $24 \mathrm{~h}$ diurnal cycle of $\mathrm{CO}$ has been resolved using the E-AERI measurements, and the impact of $\mathrm{OH}$ oxidation on $\mathrm{CO}$ in the troposphere is observed in its total columns. The amplitude of the $24 \mathrm{~h}$ diurnal cycle of $\mathrm{CO}$ at Eureka as measured by the E-AERI is slightly greater $(\sim 12 \%)$ than that in Oklahoma $(\sim 8 \%$ ) found using AERI CO retrievals (Yurganov et al., 2010). Similarly, the amplitude of the 365-day seasonal cycle of $\mathrm{CO}$ at Eureka is greater $(\sim 46 \%)$ than that in Oklahoma ( $\sim 40 \%$ ), indicating a stronger seasonal cycle of $\mathrm{CO}$ in the Arctic.

Retrievals of other trace gases, including $\mathrm{CO}_{2}, \mathrm{HCN}$, and $\mathrm{C}_{2} \mathrm{H}_{2}$ using E-AERI emission spectra are currently being evaluated. Along with CO, the E-AERI's year-round measurements of these trace gases can provide insight when investigating biomass burning events. Although the frequency of biomass burning events is decreased in the winter, the EAERI is the only instrument at Eureka capable of measuring emission products during this time when dynamical transport to the Arctic is enhanced, lengthening the potential period of studying such events. E-AERI retrievals can also be performed on a per-spectrum basis (every $7 \mathrm{~min}$ ) as opposed to hourly averaged in order to investigate the dynamical transport of trace gases (for instance, measuring the variability of $\mathrm{CO}$ as a proxy of vertical motion above Eureka). Ongoing measurements of the trace gases discussed in this paper from OPAL are being conducted (with no measurement interruptions since November 2011) to investigate their diurnal and interannual variability and for satellite validation. E-AERI trace gas measurements will continue to be used to fill the polar night gap in the PEARL dataset, providing insight into the state of the atmosphere year-round.

Acknowledgements. The Polar Environment Atmospheric Research Laboratory (PEARL) is operated by the Canadian Network for the Detection of Atmospheric Change (CANDAC). CANDAC/PEARL funding partners are: the Arctic Research Infrastructure Fund, Atlantic Innovation Fund/Nova Scotia Research Innovation Trust, Canadian Foundation for Climate and Atmospheric Science, Canadian Foundation for Innovation, Canadian Space Agency (CSA), Environment Canada (EC), Government of Canada International Polar Year, Natural Sciences and Engineering Research Council (NSERC), Ontario Innovation Trust, Ontario Research Fund, Indian and Northern Affairs Canada, and the Polar Continental Shelf Program. Spring visits to PEARL were made as part of the Canadian Arctic ACE Validation Campaigns, led by Kaley A. Walker and supported by CSA, EC, NSERC, NSERC CREATE Training Program in Arctic Atmospheric Science, and the Northern Student Training Program. Thanks to David Hudak at Environment Canada for providing MMCR data. Thanks to PEARL site manager Pierre Fogal and CANDAC operators Ashley Harrett, Alexei Khmel, Paul Loewen, Oleg Mikhailov, Keith MacQuarrie and Matt Okraszewski who have helped with the 
E-AERI measurements at PEARL. Thanks to Stephane Lantagne and Guillaume Gamache from ABB for their work installing the E-AERI, Dan Weaver for his help analyzing water vapour data, and Simone Chaudhary for her help with automating SFIT2. Thanks also to the staff at the Eureka Weather Station for their support and hospitality.

Edited by: T. von Clarmann

\section{References}

Adams, C., Strong, K., Batchelor, R. L., Bernath, P. F., Brohede, S., Boone, C., Degenstein, D., Daffer, W. H., Drummond, J. R., Fogal, P. F., Farahani, E., Fayt, C., Fraser, A., Goutail, F., Hendrick, F., Kolonjari, F., Lindenmaier, R., Manney, G., McElroy, C. T., McLinden, C. A., Mendonca, J., Park, J.-H., Pavlovic, B., Pazmino, A., Roth, C., Savastiouk, V., Walker, K. A., Weaver, D., and Zhao, X.: Validation of ACE and OSIRIS ozone and NO2 measurements using ground-based instruments at $80^{\circ} \mathrm{N}$, Atmos. Meas. Tech., 5, 927-953, doi:10.5194/amt-5-927-2012, 2012a.

Adams, C., Strong, K., Zhao, X., Bassford, M. R., Chipperfield, M., Daffer, W., Drummond, J. R., Farahani, F., Feng, W., Fraser, A., Goutali, F., Manney, G., McLinden, C., Pazmino, A., Rex, M., and Walker, K.: Severe 2011 ozone depletion assessed with 11 years of ozone, $\mathrm{NO}_{2}$, and $\mathrm{OClO}$ measurements at $80^{\circ} \mathrm{N}$, Geophys. Res. Lett., 39, L05806, doi:10.1029/2011GL050478, 2012 b.

Batchelor, R., Strong, K., Lindenmaier, R., Mittermeier, R., Fast, H., Drummond, J. R., and Fogal, P.: A New Bruker IFS 125HR FTIR Spectrometer for the Polar Environment Atmospheric Research Laboratory at Eureka, Nunavut, Canada: Measurements and Comparison with the Existing Bomem DA8 Spectrometer, J. Atmos.-Ocean. Tech., 26, 1328-1340, 2009.

Batchelor, R. L., Kolonjari, F., Lindenmaier, R., Mittermeier, R. L., Daffer, W., Fast, H., Manney, G., Strong, K., and Walker, K. A.: Four Fourier transform spectrometers and the Arctic polar vortex: instrument intercomparison and ACE-FTS validation at Eureka during the IPY springs of 2007 and 2008, Atmos. Meas. Tech., 3, 51-66, doi:10.5194/amt-3-51-2010, 2010.

Becker, E. and Notholt, J.: Ground based FTIR-emission spectroscopy of the polar atmosphere during the wintertime, Proceedings of SPIE 3106, Munich, Germany, 154-158, 1997.

Bianchini, G., Cortesi, U., and Carli, B.: Emission Fourier transform spectroscopy for remote sensing of the Earth's atmosphere, Annals Geophys., 46, 205-222, 2003.

Bianchini, G., Palchetti, L., Muscari, G., Fiorucci, I., Di Girolamo, P., and Di Iorio, T.: Water vapor sounding with the far infrared REFIR-PAD spectroradiometer from a high-altitude groundbased station during the ECOWAR campaign, J. Geophys. Res., 116, D02310, doi:10.1029/2010JD014530, 2010.

Clough, S. A., Iacono, M., and Moncet, J.-L.: Line-by-Line Calculations of Atmospheric Fluxes and Cooling Rates: Application to Water Vapor, J. Geophys. Res., 97, 15761-15785, 1992.

Fast, H., Mittermeier, R., and Makino, Y.: A ten-year record of Arctic trace gas total column measurements at Eureka, Canada, from 1997 to 2006, Atmos.-Ocean, 49, 67-94, 2011.

Fisher, H. and Oelhaf, H.: Remote sensing of vertical profiles of atmospheric trace constituents with MIPAS limb-emission spectrometers, Appl. Optics, 35, 2787-2796, 1996.
Fraser, A., Adams, C., Drummond, J. R., Goutail, F., Manney, G., and Strong, K.: The Polar Environment Atmospheric Research Laboratory UV-visible Ground-Based Spectrometer: First measurements of $\mathrm{O}_{3}, \mathrm{NO}_{2}, \mathrm{BrO}$, and $\mathrm{OClO}$ columns, J. Quant. Spectrosc. Ra., 110, 986-1004, 2009.

Hase, F., Hannigan, J. W., Coffey, M. T., Goldman, A., Hopfner, M., Jones, N. B., Rinsland, C. P., and Wood, S. W.: Intercomparison of retrieval codes used for the analysis of highresolution, ground-based FTIR measurements, J. Quant. Spectrosc. Ra., 87, 25-52, 2004.

Hendrick, F., Pommereau, J.-P., Goutail, F., Evans, R. D., Ionov, D., Pazmino, A., Kyrö, E., Held, G., Eriksen, P., Dorokhov, V., Gil, M., and Van Roozendael, M.: NDACC/SAOZ UV-visible total ozone measurements: improved retrieval and comparison with correlative ground-based and satellite observations, Atmos. Chem. Phys., 11, 5975-5995, doi:10.5194/acp-11-5975-2011, 2011.

International Organization of Standardization: Guide to the Expression of Uncertainty in Measurement, 1st Edn., US Government Printing Office, Washington, 101 pp., 1993.

Knuteson, R., Revercomb, H., Best, F., Ciganovich, N., Dedecker, R., Dirkx, T., Ellington, S., Feltz, W., Garcia, R., Howell, H., Smith, W., Short, J., and Tobin, D.: Atmospheric Emitted Radiance Interferometer, Part II: Instrument Performance, J. Atmos. Ocean. Tech., 21, 1777-1789, 2004.

Lam, K. S., Savastiouk, V., Fung, W., Chan, T., and Lamb, K.: Recalculation of 11-year total ozone of Brewer spectrophotometer 115, J. Geophys. Res., 112, D15104, doi:10.1029/2006JD008178, 2007.

Lindenmaier, R.: Studies of Arctic Middle Atmospheric Chemistry using Infrared Absorption Spectroscopy. PhD Thesis, University of Toronto, 308 pp., 2012.

Lindenmaier, R., Batchelor, R., Strong, K., Fast, H., Goutail, F., Kolonjari, F., McElroy, C. T., Mitermeier, R., and Walker, K.: An evaluation of infrared microwindows for ozone retrievals using the Eureka Bruker 125HR Fourier transform spectrometer, J. Quant. Spectrosc. Ra., 111, 569-585, 2010.

Lindenmaier, R., Strong, K., Batchelor, R. L., Chipperfield, M. P., Daffer, W. H., Drummond, J. R., Duck, T. J., Fast, H., Feng, W., Fogal, P. F., Kolonjari, F., Manney, G. L., Manson, A., Meek, C., Mittermeier, R. L., Nott, G. J., Perro, C., and Walker, K. A.: Unusually low ozone, $\mathrm{HCl}$, and $\mathrm{HNO}_{3}$ column measurements at Eureka, Canada during winter/spring 2011, Atmos. Chem. Phys., 12, 3821-3835, doi:10.5194/acp-12-3821-2012, 2012.

Manney, G., Santee, M., Rex, M., Livesey, N., Pitts, M., Veefkind, P., Nash, E., Wohltmann, I., Lephmann, R., Froidevaux, L., Poole, L., Schoeberl, M., Haffner, D., Davies, J., Dorokhov, V., Gernandt, H., Johnson, B., Kivi, R., Kyro, E., Larsen, N., Levelt, P., Makshtas, A., McElroy, C. T., Nakajima, H., Parrondo, M., Tarasick, D., Gathen, P., Walker, K. A., and Zinoviev, N.: Unprecedented Arctic ozone loss in 2011, Nature, 478, 469-475, 2011.

Mariani, Z., Strong, K., Wolff, M., Rowe, P., Walden, V., Fogal, P. F., Duck, T., Lesins, G., Turner, D. S., Cox, C., Eloranta, E., Drummond, J. R., Roy, C., Turner, D. D., Hudak, D., and Lindenmaier, I. A.: Infrared measurements in the Arctic using two Atmospheric Emitted Radiance Interferometers, Atmos. Meas. Tech., 5, 329-344, doi:10.5194/amt-5-329-2012, 2012. 
Meier, A., Goldman, A., Manning, P. S., Stephen, T. M., Rinsland, C. P., Jones, N. B., and Wood, S. W.: Improvements to air mass calculations for ground-based infrared measurements, J. Quant. Spectrosc. Ra., 83, 109-113, 2004.

Park, J. H., Russell III, J. M., Gordley, L. L., Drayson, S. R., Benner, D. C., Mclnerney, J. M., Gunson, M. R., Toon, G. C., Sen, B., Blavier, J. F., Webster, C. R., Zipf, E. C., Erdman, P., Schmidt, U., and Schiller, C.: Validation of Halogen Occultaiton Experiment $\mathrm{CH}_{4}$ measurements from the UARS, J. Geophys. Res., 101, 10183-10203, 1996.

Platt, U. and Stutz, J.: Differential Optical Absorption Spectroscopy, edited by: Guzzi, R., Lanzerotti, L. J., Imboden, D., and Platt, U., Springer, Germany, 175-285, 2008.

Pommereau, J. P. and Goutail, F.: $\mathrm{O}_{3}$ and $\mathrm{NO}_{2}$ ground-based measurements by visible spectrometry during Arctic winter and spring 1988, Geophys. Res. Lett., 15, 891-894, 1988.

Pougatchev, N., Connor, B., and Rinsland, C.: Infrared measurements of the ozone vertical distribution above Kitt Peak, J. Geophys. Res., 100, 16689-16697, doi:10.1029/95JD01296, 1995.

Raffalski, U., Hochschild, G., Kopp, G., and Urban, J.: Evolution of stratospheric ozone during winter 2002/2003 as observed by a ground-based millimetre wave radiometer at Kiruna, Sweden, Atmos. Chem. Phys., 5, 1399-1407, doi:10.5194/acp-5-13992005, 2005.

Randel, W., Chanin, M.-L., and Michaut, C.: Intercomparison of Middle Atmosphere Climatologies, SPARC Report No. 3, WCRP 116, WMO/TD 1142, http://www.sparc-climate.org/ publications/sparc-reports/sparc-report-no3/ (last access: June 2013), 2002.

Ravishankara, A. R., Daniel, J. S., and Portmann, R. W.: Nitrous oxide $\left(\mathrm{N}_{2} \mathrm{O}\right)$ : the dominant ozone-depleting substance emitted in the 21st century, Science, 326, 123-125, 2009.

Rinsland, C. P., Jones, N., Connor, B., Logan, J., Pougatchev, N., Goldman, A., Murcray, F., Stephen, T., Pine, A., Zander, R., Mahieu, E., and Demoulin, P.: Northern and Southern Hemisphere ground-based infrared spectroscopic measurements of tropospheric carbon monoxide and ethane, J. Geophys. Res., 103, 28197-28217, 1998.

Rodgers, C. D.: Retrieval of atmospheric temperature and composition from remote measurements of thermal radiation, Rev. Geophys., 14, 609-624, 1976.

Rodgers, C. D.: Characterization and error analysis of profiles retrieved from remote sounding measurements, J. Geophys. Res., 95, 5587-5595, 1990.

Rodgers, C. D.: Inverse methods for atmospheric sounding: theory and practice, in: Series on atmospheric, oceanic and planetary physics, vol. 2., World Scientific Publishing Co. Pte. Ltd., New Jersey, 2000.

Rodgers, C. D. and Connor, B. J.: Intercomparison of remote sounding instruments, J. Geophys. Res., 108, 1-14, 2003.
Rothman, L. S., Gordon, I. E., Barbe, A., Benner, D. C., Bernath, P. F., Birk, M., Boudon, V., Brown, L. R., Camparague, A., Champion, J.-P., Chance, K., Coudert, L. H., Dana, V., Devi, V. M., Fally, S., Flaud, J.-M., Gamache, R. R., Goldman, A., Jacquemart, D., Kleiner, I., Lacome, N., Lafferty, W. J., Mandin, J.-Y., Massie, S., Mikhailenko, S. N., Miller, C. E., Moazzen-Ahmadi, M., Naumenko, O. V., Nikitin, A. V., Orphal, J., Perevalov, V. I., Perrin, A., Predoi-Cross, A., Rinsland, C., Rotger, M., Simeckova, M., Smith, M., Sung, K., Tashkun, S. A., Tennyson, J., Vandaele, A. C., Toth, R., and Vander Auwera, J.: The HITRAN 2008 molecular spectroscopic database, J. Quant. Spectrosc. Ra., 110, 533-572, 2009.

Savastiouk, V. and McElroy, C. T.: Brewer spectrophotometer total ozone measurements made during the 1998 Middle Atmosphere Nitrogen Trend Assessment (MANTRA) campaign, Atmos.Ocean, 43, 315-324, 2005.

Stohl, A.: Characteristics of atmospheric transport into the Arctic atmosphere, J. Geophys. Res., 111, D11306, doi:10.1029/2005JD006888, 2006.

Stremme, W., Krueger, A., Harig, R., and Grutter, M.: Volcanic $\mathrm{SO}_{2}$ and $\mathrm{SiF}_{4}$ visualization using 2-D thermal emission spectroscopy - Part 1: Slant-columns and their ratios, Atmos. Meas. Tech., 5, 275-288, doi:10.5194/amt-5-275-2012, 2012.

Tobin, D. C., Best, F. A., Brown, P. D., Clough, S. A., Dedecker, R., Ellingson, R., Garcia, R., Howell, H., Knuteson, R., Mlawer, E., Revercomb, H., Short, J., van Deist, P., and Walden, V.: Downwelling spectral radiance observations at the SHEBA ice station: Water vapour continuum measurements from 17 to $26 \mu \mathrm{m}$, J. Geophys. Res., 104, 2081-2092, 1999.

Vigouroux, C., De Mazière, M., Errera, Q., Chabrillat, S., Mahieu, E., Duchatelet, P., Wood, S., Smale, D., Mikuteit, S., Blumenstock, T., Hase, F., and Jones, N.: Comparisons between groundbased FTIR and MIPAS $\mathrm{N}_{2} \mathrm{O}$ and $\mathrm{HNO}_{3}$ profiles before and after assimilation in BASCOE, Atmos. Chem. Phys., 7, 377-396, doi:10.5194/acp-7-377-2007, 2007.

Waldmann, I., Tinetti, G., Drossart, P., Swain, M., Deroo, P., and Griffith, C.: Ground-based near infrared emission spectroscopy of HD 189733B, Astrophys. J., 744, 35, doi:10.1088/0004637X/744/1/35, 2012.

Warneke, C., Froyd, K., Brioude, J., Bahreini, R., Brock, C., Cozic, J., de Gouw, J., Fahey, D., Ferrare, R., Holloway, J., Middlebrook, A., Miller, L., Montzka, S., Schwartz, J., Sodermann, H., Spackman, J., and Stohl, A.: An important contribution to springtime Arctic aerosol from biomass burning in Russia, Geophys. Res. Lett., 37, L01801, doi:10.1029/2009GL041816, 2010.

Yurganov, L., McMillan, W., Wilson, C., Fischer, M., Biraud, S., and Sweeney, C.: Carbon monoxide mixing ratios over Oklahoma between 2002 and 2009 retrieved from Atmospheric Emitted Radiance Interferometer spectra, Atmos. Meas. Tech., 3, 1319-1331, doi:10.5194/amt-3-1319-2010, 2010. 